\title{
IN VITRO VALIDATION OF BIOMEDICAL POLYESTER-BASED SCAFFOLDS: POLY(LACTIDE-CO-GLYCOLIDE) AS MODEL- CASE
}

\section{O. Gil-Castell ${ }^{1}$, J. D. Badia ${ }^{1,2,3}$, I. Ontoria-Oviedo ${ }^{4}$, D. Castellano ${ }^{4}$, B. Marco ${ }^{5}$, A. Rabal $^{5}$, J. J. Bou ${ }^{6}$, A. Serra ${ }^{2}$, L. Monreal ${ }^{1}$, M. Blanes ${ }^{5}$, P. Sepúlveda ${ }^{4}$, A. Ribes- Greus ${ }^{1, *}$}

This is an open-access version, according to http://www.sherpa.ac.uk/romeo/issn/0142-9418/

Full text available at https://www.sciencedirect.com/science/article/pii/S0142941817315647

\section{DOI: https://doi.org/10.1016/j.polymertesting.2018.01.027}

Please, cite it as:

O. Gil-Castell, J. D. Badia, I. Ontoria-Oviedo, D. Castellano, B. Marco, A. Rabal, J. J. Bou, A. Serra, L. Monreal, M. Blanes, P. Sepúlveda, A. Ribes-Greus. In vitro validation of biomedical polyester-based scaffolds: Poly(lactide-co-glycolide) as model-case. Polymer Testing 2018;66:256-267

${ }^{1}$ Instituto de Tecnología de Materiales (ITM), Universitat Politècnica de València, Camino de Vera s/n, 46022 Valencia, Spain

${ }^{2}$ Departament de Química Orgànica i Analítica, Universitat Rovira i Virgili,

C/ Marcel·lí Domingo s/n, 43007 Tarragona, Spain

${ }^{3}$ Departament d'Enginyeria Química. Escola Tècnica Superior d'Enginyeria, Universitat de València, Av. de la Universitat, s/n, 46100 Burjassot, Spain

${ }^{4}$ Unidad de Regeneración y Trasplante Cardíaco, Instituto de Investigación Sanitaria La Fe, Av. Fernando Abril Martorell Torre A, 46026 Valencia, Spain

${ }^{5}$ Grupo de Investigación de Acabados Técnicos, Salud y Medioambiente, Instituto Tecnológico Textil (AITEX), Plaza Emilio Sala 1, 03801 Alcoy, Spain

${ }^{6}$ Departament d'Enginyeria Química, Universitat Politècnica de Catalunya, Av. Diagonal 647 (ETSEIB), 08028 Barcelona, Spain

*Corresponding author:

A. Ribes-Greus aribes@ter.upv.es

Tel. 0034630125695 


\title{
IN VITRO VALIDATION OF BIOMEDICAL POLYESTER-BASED SCAFFOLDS: POLY(LACTIDE-CO-GLYCOLIDE) AS MODEL- CASE
}

\author{
O. Gil-Castell ${ }^{1}$, J. D. Badia ${ }^{1,2,3}$, I. Ontoria-Oviedo ${ }^{4}$, D. Castellano ${ }^{4}$, B. Marco ${ }^{5}$, A. \\ Rabal $^{5}$, J. J. Bou ${ }^{6}$, A. Serra ${ }^{2}$, L. Monreal ${ }^{1}$, M. Blanes ${ }^{5}$, P. Sepúlveda ${ }^{4}$, A. Ribes- \\ $\underline{\text { Greus }}{ }^{1, *}$
}

\begin{abstract}
Monitoring and understanding the in vitro behaviour of polyester based scaffolds both comprising the study of the hydrolytic degradation and the cell seeding viability is essential to ensure the desired functionality, according to a given biomedical purpose. As a model case to compare the performance of techniques to monitor the in vitro behaviour, poly(lactide-co-glycolide) (PLGA) scaffolds were chosen.

The in vitro hydrolytic degradation of PLGA scaffolds was carried out in water and phosphate buffered saline (PBS). The evolution of the mass loss, the molar mass, the thermal properties and the surface morphology were monitored. The hydrolytic degradation media was correspondingly evaluated by means of the study of the $\mathrm{pH}$, the amount of acid released and the conductivity.

In addition, the in vitro biocompatibility regarding the cell culture viability was studied under physiological conditions. The cellular adhesion, cellular ability to proliferate on the scaffold, the scaffold inflammatory profile and the effect of the scaffold degradation compounds on the cells were assessed.

A comparative analysis of the exploited techniques in terms of promptness of identification, depth of knowledge, simplicity of obtaining results and cost of the technique was implemented. The results showed that, depending on the balance between the interest in ascertaining the trigger of degradation or deep into the knowledge of the causes and effects of cell culture viability, an appropriate plan of analysis of the validation of polyester-based scaffolds could be designed.
\end{abstract}

\section{Keywords}

Scaffold; polyester; poly(lactide-co-glycolide) (PLGA); in vitro validation; biocompatibility; polymer testing 
O. Gil-Castell, J. D. Badia, I. Ontoria-Oviedo, D. Castellano, B. Marco, A. Rabal, J. J. Bou, A. Serra, L. Monreal, M. Blanes, P. Sepúlveda, A. Ribes-Greus. In vitro validation of biomedical polyester-based scaffolds: Poly(lactide-coglycolide) as model-case. Polymer Testing 2018;66:256-267

\section{Introduction}

Polyesters are one of the most used polymeric materials for biomedical applications such as sutures, implants, artificial skin and controlled drug release devices [1]-[4]. Such is the case of the poly(lactide) (PLA), poly(glycolide) (PGA), poly(E-caprolactone) (PCL) or poly(lactide-coglycolide) (PLGA) [5]-[9]. The irruption of electrospinning in tissue engineering has boosted the technology of production of biomaterials comprising fibrous architectures which diameters can vary from several tens to hundreds of nanometres, mimicking the native extracellular matrix and allowing enough porosity to facilitate cellular growth [10]-[12]. Precisely, the tuning of these scaffolds is required to ensure a balance between enough time of structural endurance to permit angiogenesis, and appropriate degradation profiles to be decomposed without delivery of toxic low molar mass compounds [13]. In this sense, the development of protocols to establish the structure-to-performance relationship of biomedical scaffolds still represents a matter of interest.

The use of poly(lactide-co-glycolide) (PLGA) as biopolymeric scaffold is well-extended due to its equilibrium of performance of durability and bioassimilation trends [14], [15], and therefore was taken as model polyester in this work. An equilibrated water-affinity with reasonable degradation times has been found for 50:50 PLGA where the methyl side-groups of the PLA macrosegments confer hydrophobicity to the copolymer [16]. The mechanism of degradation of PLGA under abiotic aqueous environments takes place through hydrolysis of the ester bonds, auto-catalysed by carboxylic groups, exponentially increasing along the exposure time [17]. These microstructural changes induce the formation of macroscopic pores or cracks, and the loss of monomeric and oligomeric species, thus reducing the mass of the polymers and finally decomposing their architecture until bioassimilation or excretion [18]. PLGA permits different preparations and designs. For instance, Farahani et al. studied 50:50 PLGA as compressed discs for implants [19], Vey et al. assessed the degradation of cast films [20] and Wu et al. the biodegradation of PLGA rods with different compositions [21]. As electrospun scaffolds, some characterisation studies of the in vitro degradation have been reported [7], [22]-[28], generally considering the monitoring of mass-loss and molar mass along hydrolytic exposure.

Depending on the area of application and the purpose of the analysis, the focus on the research can vary from the deepest knowledge of the degradation mechanisms from the material science point of view [29]-[32], to a fast reference trial of materials to identify the relative times of decomposition and thus further infer the response under biological conditions in medical studies [7], [24], [33], [34]. Therefore, the aim of this work was to compare the suitability of the set of analytical techniques schematised in Figure 1 to validate the in vitro behaviour of a model electrospun polyester (PLGA) through the study of its hydrolytic degradation and biocompatibility. For this purpose, the hydrolytic degradation profiles were monitored in ultrapure water and phosphate buffer solution (PBS) at $37{ }^{\circ} \mathrm{C}$. The scaffold was characterised by gravimetric analysis, size exclusion chromatography (SEC), differential scanning calorimetry (DSC) and field emission scanning electron microscopy (FE-SEM) while the degradation media was monitored by $\mathrm{pH}$ measurement, titration of released acids and conductometry. Biocompatibility was studied in terms of cellular adhesion, morphology and proliferation of cells, the inflammatory profile, and the effect of the scaffold degradation compounds on the cell viability were assessed by means of immunofluorescence, FE-SEM, methyl tetrazolium (MTT) and pyrogenic assays, respectively. Aspects such as promptness of identification, depth of knowledge, simplicity of obtaining results and cost of the techniques were taken into account as a basis for specialists to set up an appropriate plan of analysis of the degradation and durability of polyester-based scaffolds. 
O. Gil-Castell, J. D. Badia, I. Ontoria-Oviedo, D. Castellano, B. Marco, A. Rabal, J. J. Bou, A. Serra, L. Monreal, M. Blanes, P. Sepúlveda, A. Ribes-Greus. In vitro validation of biomedical polyester-based scaffolds: Poly(lactide-coglycolide) as model-case. Polymer Testing 2018;66:256-267

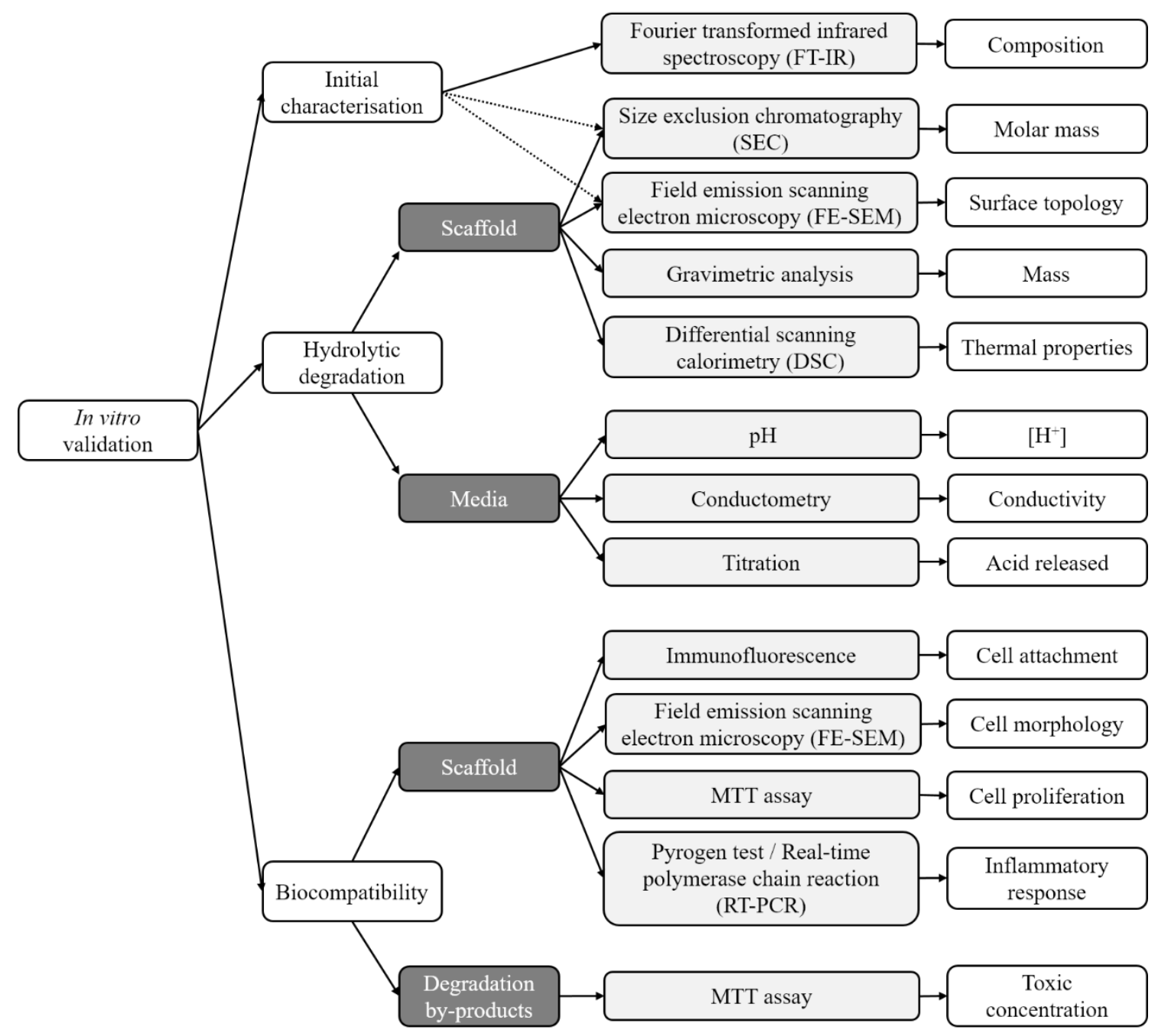

Figure 1. Scheme of the in vitro validation techniques used in this study along with the most representative indicators for each technique.

\section{Materials and methods}

\subsection{Materials}

The 50:50 DL-PLGA used in this study was provided by Lactel Absorbable Polymers (Birmingham, USA). Dimethylformamide (DMF) was used as solvent for electrospinning. For the hydrolytic degradation procedure, ultra-pure water of type 1 (ISO 3696) [35], Dulbecco's Phosphate Buffered Saline solution (PBS, D1408) and $\mathrm{NaOH} 1 \mathrm{M}$ for adjusting $\mathrm{pH}$ in PBS, were used. All these reactants, except water, were supplied by Sigma-Aldrich (San Luis, USA) and were used without further purification. For the in vitro biocompatibility tests paraformaldehyde (PFA) from VWR Chemicals and 4',6-diamidino-2-phenylindole (DAPI) from Sigma-Aldrich were used.

\subsection{Scaffold preparation}

The PLGA scaffolds were obtained by means of an Yflow Electrospinner 2.2.D-350 (Málaga, Spain). It consisted in double polarization, integrated drum collector control panel and robotized stage to move the electrospinning source in an alternative fashion covering a $400 \times 400 \mathrm{~mm}^{2}$ area. PLGA solution was prepared at a $30 \%$ by weight in pure DMF under gentle stirring overnight at 
O. Gil-Castell, J. D. Badia, I. Ontoria-Oviedo, D. Castellano, B. Marco, A. Rabal, J. J. Bou, A. Serra, L. Monreal, M. Blanes, P. Sepúlveda, A. Ribes-Greus. In vitro validation of biomedical polyester-based scaffolds: Poly(lactide-coglycolide) as model-case. Polymer Testing 2018;66:256-267

room temperature. The polymer solution was electrospun at a $14 \mathrm{kV}$ voltage, with a tip-tocollector distance of $20 \mathrm{~cm}$ and a solution flow rate of $1 \mathrm{ml} \cdot \mathrm{h}^{-1}$. The solution jet emerging from the stainless steel wire $(0.9 \mathrm{~mm}$ inner diameter) used as the positive electrode, was collected on a waxed paper. Scaffolds, with an average thickness of $1.35 \times 10^{-2} \mathrm{~mm}$, were obtained and dried over $12 \mathrm{~h}$ under vacuum to facilitate the removal of residual solvent and moisture.

\subsection{In vitro degradation}

The PLGA scaffolds were subjected to hydrolytic degradation under ultra-pure water and phosphate buffer saline solution (PBS), according to the international norm ISO 10993-13:2010, method 4.3 [36]. Shortly, the initial electrospun scaffolds were cut into rectangular specimens with a mass around $10 \mathrm{mg}$. The specimens were weighed $\left(m_{0}\right)$ and placed in a previous weighed vial $\left(m_{\text {vial }}\right) .10 \mathrm{ml}$ of degradation medium were introduced, then the vials were sealed with polytetrafluoroethylene (PTFE) threaded plugs and placed in a thermostatically controlled oven at $37^{\circ} \mathrm{C}$. The $\mathrm{pH}$ of the PBS solution was adjusted to 7.4 with $\mathrm{NaOH} 1 \mathrm{M}$. Twelve extractions were considered along the hydrolytic degradation over 150 days. In order to monitor the process, after certain periods of time, samples were withdrawn from the environment by triplicate. Solid and liquid fractions were separated. The liquid fraction was analysed immediately after extraction, while the solid fraction followed a washing-drying-keeping procedure before further analysis. Actually, those specimens coming from the saline buffer were washed with deionized water and then, along with specimens coming from water environment, were dried under vacuum to constant mass into their degradation vials $\left(m_{d r y}\right)$ and saved for further analysis.

\subsection{Scaffold characterisation}

\subsubsection{Mass loss monitoring}

The residual mass of the samples (\% mass) was determined by the Equation 3,

$$
\% \text { mass }=\frac{m_{d r y}-m_{\text {vial }}}{m_{0}} \times 100 \quad(\text { Equation 3) }
$$

where $m_{0}, m_{\text {vial }}$ are the initial mass of the specimen, and the vial, respectively; and $m_{d r y}$, the mass of the vacuum dry assembly sample-vial after degradation.

\subsubsection{Size exclusion chromatography (SEC)}

Size exclusion chromatography (SEC) analyses were carried out by means of an Agilent Infinity 1260 chromatograph. Separation was performed with a Jordi Associates mixed bed fluorinated column (permeation range: $100-10 \times 10^{6}$ Dalton). All the samples were dissolved in mobile phase of hexafluoroisopropanol (HFIP) containing $2.72 \mathrm{~g} \cdot \mathrm{L}^{-1}$ of sodium trifluoroacetate (NaTFA). This solvent was previously degassed by vacuum filtration over PTFE $0.45 \mu \mathrm{m}$ pore membranes. Flow rate was set at $1 \mathrm{ml} \cdot \mathrm{min}^{-1}$ and $100 \mu \mathrm{L}$ samples of about $0.1 \%$ concentration were injected. Detection was conducted by UV-vis-detector. Monodisperse PMMA samples from SigmaAldrich and Agilent were used for previous calibration. The specimens were characterised in triplicates and the averages were taken as representative values.

\subsubsection{Fourier transformed infrared spectroscopy (FT-IR)}

The assurance of the composition of the scaffolds was determined via attenuated total reflectance (ATR) in a Thermo Nicolet 5700 Fourier transform infrared spectrometer (FT-IR). The average 
O. Gil-Castell, J. D. Badia, I. Ontoria-Oviedo, D. Castellano, B. Marco, A. Rabal, J. J. Bou, A. Serra, L. Monreal, M. Blanes, P. Sepúlveda, A. Ribes-Greus. In vitro validation of biomedical polyester-based scaffolds: Poly(lactide-coglycolide) as model-case. Polymer Testing 2018;66:256-267

spectra were collected from 64 accumulations with a resolution of $4 \mathrm{~cm}^{-1}$ in the $4000-400 \mathrm{~cm}^{-1}$ range, from eight different locations of the same specimen.

\subsubsection{Differential scanning calorimetry (DSC)}

Calorimetric data were obtained by differential scanning calorimetry (DSC) with a MettlerToledo DSC 820 series. The DSC equipment was calibrated following the procedure of In and Zn standards. The samples, with a mass of about $4 \mathrm{mg}$ were analysed between -20 and $220^{\circ} \mathrm{C}$ with a heating rate of $10^{\circ} \mathrm{C} \cdot \mathrm{min}^{-1}$. All experiments were run under nitrogen atmosphere $\left(50 \mathrm{ml} \cdot \mathrm{min}^{-}\right.$ ${ }^{1}$ ). The specimens were characterised at least in triplicates and the averages of temperatures were taken as representative values.

\subsubsection{Field emission scanning electron microscopy (FE-SEM)}

The surface morphology of specimens was analysed by means of a Zeiss Ultra 55 field emission scanning electron microscope (FE-SEM). The samples were cut into small pieces and dried at 50 ${ }^{\circ} \mathrm{C}$ in a vacuum oven for $24 \mathrm{~h}$ and then kept in a desiccator during $48 \mathrm{~h}$. Afterwards, the specimens were mounted on metal studs and sputter-coated with a platinum layer during $10 \mathrm{~s}$ using a Leica EM MED020. Testing was performed at room temperature with a $3 \mathrm{kV}$ voltage. The fibre diameters were measured from the FE-SEM micrographs at random locations $(n=100)$ with the aid of Image $\mathbf{J}$ software.

\subsection{Characterisation of the degradation media}

\subsection{1. $\mathrm{pH}$ and conductivity measurements}

The $\mathrm{pH}$ and conductivity of the degradation media were measured at room temperature by means of Crison pH25 and Crison CM35 devices. Three buffer solutions from Crison were used to calibrate the pH-meter: $\mathrm{pH} 4.01$ (phthalate buffer solution), $\mathrm{pH} 7.00$ (phosphate buffer solution), pH 10.01 (borate buffer solution). Different $\mathrm{KCl}$ solutions $(0.1 \mathrm{M}, 0.01 \mathrm{M}$ and $0.001 \mathrm{M})$ with conductivities of $12.88 \mathrm{mS} \cdot \mathrm{cm}^{-1}, 1413 \mu \mathrm{S} \cdot \mathrm{cm}^{-1}$ and $147 \mu \mathrm{S} \cdot \mathrm{cm}^{-1}$, respectively, were used to calibrate the conductometer. Measurements were carried out in three different specimens per sample and the averages were taken as representative values.

\subsubsection{Titration}

The amount of released acid was estimated by means of a titration of the degradation medium. In this method, only monomeric units of lactic and glycolic acids are supposed to be released according to the methodology proposed by Vey et al. [20]. Aqueous solutions of lactic and glycolic acids were prepared at $0.01 \mathrm{M}$ in order to establish an additive pattern curve which related the concentration of each compound with the $\mathrm{pH}$.

\subsection{In vitro biocompatibility}

\subsubsection{Cell culture}

Human fibroblasts were cultured in high-glucose Dulbecco's Modified Eagle's Medium (SigmaAldrich) supplemented with $10 \%$ of foetal bovine serum (FBS), penicillin $\left(100 \mathrm{U} \cdot \mathrm{ml}^{-1}\right)$ and streptomycin $\left(100 \mu \mathrm{g} \cdot \mathrm{ml}^{-1}\right)$ (Gibco). Human keratinocytes were cultured in low-glucose Dulbecco's Modified Eagle's Medium (Sigma-Aldrich) supplemented with 10\% of chelated FBS, penicillin $\left(100 \mathrm{U} \cdot \mathrm{ml}^{-1}\right)$ and streptomycin $\left(100 \mu \mathrm{g} \cdot \mathrm{ml}^{-1}\right)$. Cells were harvested for passaging with trypsin-EDTA ( $0.25 \%$ trypsin and $0.02 \%$ EDTA) solution. 
O. Gil-Castell, J. D. Badia, I. Ontoria-Oviedo, D. Castellano, B. Marco, A. Rabal, J. J. Bou, A. Serra, L. Monreal, M. Blanes, P. Sepúlveda, A. Ribes-Greus. In vitro validation of biomedical polyester-based scaffolds: Poly(lactide-coglycolide) as model-case. Polymer Testing 2018;66:256-267

\subsubsection{Cell-adhesion assay}

In order to evaluate the cell attachment to the scaffolds, 40000 cells were plated onto $1 \mathrm{~cm}^{2}$ of the polymer sheet in triplicates. Cells were allowed to attach for $30 \mathrm{~min}$ and then cultured in the appropriate medium for 48 and $96 \mathrm{~h}$. Thereafter, scaffolds were washed with cold PBS and fixed for 20 min with $2 \%$ PFA at room temperature, then washed again and finally stained with 4',6diamidino-2-phenylindole (DAPI) for $10 \mathrm{~min}$ at RT. Images were acquired in a fluorescence microscope.

As well, to better characterize the cell attachment and morphology, scanning electron microscope images were acquired. Briefly, 40000 cells $\cdot \mathrm{cm}-2$ were seeded onto the scaffold and cultured for $48 \mathrm{~h}$. Then, the cells were foxed with $3 \%$ glutaraldehyde solution during $60 \mathrm{~min}$ at $37{ }^{\circ} \mathrm{C}$ and subsequently critical point dried (CPD). This procedure removes liquids from the specimen and avoids surface tension effects, by never allowing a liquid/gas interface to develop [37]. The CPD protocol considered was dehydration through a graded series of ethanol $(10 \%, 20 \%, 30 \%, 50 \%$ and $70 \%$, once for $10 \mathrm{~min}$ at each step), and then immersed in $100 \%$ ethanol twice for $30 \mathrm{~min}$ each. The tissues were then transferred to a Quorum Technologies Polaron E3000 critical point dryer, using liquefied carbon dioxide as transitional fluid. Finally, samples were sputter-coated and analysed according to the protocol described in section 2.4.5.

\subsubsection{MTT assay}

Human fibroblasts were plated at a density of $40000 \mathrm{cell} \cdot \mathrm{cm}^{-2}$ onto scaffolds. Proliferation was measured in triplicates after 48 and $96 \mathrm{~h}$ using thiazolyl blue tetrazolium bromide (MTT assay; Sigma-Aldrich), following the manufacturer's instructions. Absorbance was measured at $550 \mathrm{~nm}$ using a plate reader Halo Led 96 (Dynamica Scientific Ltd.).

To evaluate the toxicity of the compounds obtained from the scaffold degradation (PLGA), different concentrations of lactic and glycolic acid were tested (mM): 0, 10, 20, 30, 40, 50 and 60. Fibroblast and keratinocytes were seeded (10000 cells per well of a 96 well plate) and incubated during $24 \mathrm{~h}$ with the determined concentrations.

\subsubsection{Pyrogen test}

Blood was obtained from the Valencian Blood Tissue Bank after informed consent and was processed as described previously [33]. Briefly, peripheral blood mononuclear cells (PBMCs) were isolated by Ficoll density gradient centrifugation and incubated in triplicates with the PLGA scaffolds during $5 \mathrm{~h}$ at a density of $6 \times 10^{6} \mathrm{cells} \cdot \mathrm{ml}^{-1}$. RNA was obtained using QIAzol Lysis Reagent and purification was carried out with RNeasy Plus Mini Kit (Qiagen). RNA was quantified by spectrometry using a NanoDrop ND-2000 (NanoDrop Technologies). The same procedure was used with PBMCs incubated with poly(3-hydroxybutyrate) (PHB) scaffolds.

\subsubsection{Reverse transcription and real-time polymerase chain reaction (RT-PCR)}

cDNA was synthesized from $1 \mu \mathrm{g}$ of total purified RNA using the High-Capacity cDNA Reverse Transcription kit (Applied Biosystems). Primers were designed [33] and RT-PCR was performed as previously described [38]. The following pro-inflammatory cytokines were analyzed: IL-1 $\beta$, IL-6, IL-10 and TNF- $\alpha$, the gene expression levels were normalized to the human housekeeping ACTB. Data are represented as the average from triplicate samples. 
O. Gil-Castell, J. D. Badia, I. Ontoria-Oviedo, D. Castellano, B. Marco, A. Rabal, J. J. Bou, A. Serra, L. Monreal, M. Blanes, P. Sepúlveda, A. Ribes-Greus. In vitro validation of biomedical polyester-based scaffolds: Poly(lactide-coglycolide) as model-case. Polymer Testing 2018;66:256-267

\subsubsection{Statistical Analysis}

The results in this study are expressed as mean \pm standard deviation (SD). In the biocompatibility assays, comparison between experimental conditions were performed with Mann-Whitney test. Differences were considered statistically significant at $\mathrm{P}<0.05$ with a $95 \%$ confidence interval. Analyses were conducted with GraphPad Prism 5 software.

\section{Results and discussion}

\subsection{Initial characterisation of the scaffold}

The validation of a given scaffold for tissue engineering starts from an initial or preliminary characterisation of this device. Accordingly, it is essential to evaluate some fundamental features such as the surface morphology, the fibre diameter, the porosity, the chemical composition and the molar mass. These are key factors that will determine the behaviour of the scaffold during application.

Figure 2 shows a FE-SEM image of the surface morphology, along with the histogram of diameters of the electrospun PLGA scaffolds. For satisfactory cell attachment and proliferation, the fibre diameter $(d)$ must remain in the nanoscale range which is crucial and necessary to mimic the extracellular matrix (ECM) size [39]. For the case of PLGA scaffolds, a uniform non-woven nanofibrous structure was observed.

The estimated porosity $(\varnothing)$ of the scaffold was calculated by means of the Equation 4 ,

$$
\varnothing(\%)=\left(1-\frac{\rho}{\rho_{0}}\right) \times 100 \quad(\text { Equation 4) }
$$

where $\rho$ is the density of electrospun sheet considering a thickness of $1.35 \cdot 10^{-3} \mathrm{~cm}$ and a density $\left(\rho_{0}\right)$ of $1.25 \mathrm{~g} \cdot \mathrm{cm}^{-3}$ for the bulk PLGA [25]. As well, the surface density $\left(\rho_{s}\right)$, referred to the mass per unit area, was calculated by weighing a piece of the scaffold and normalised to the selected area.
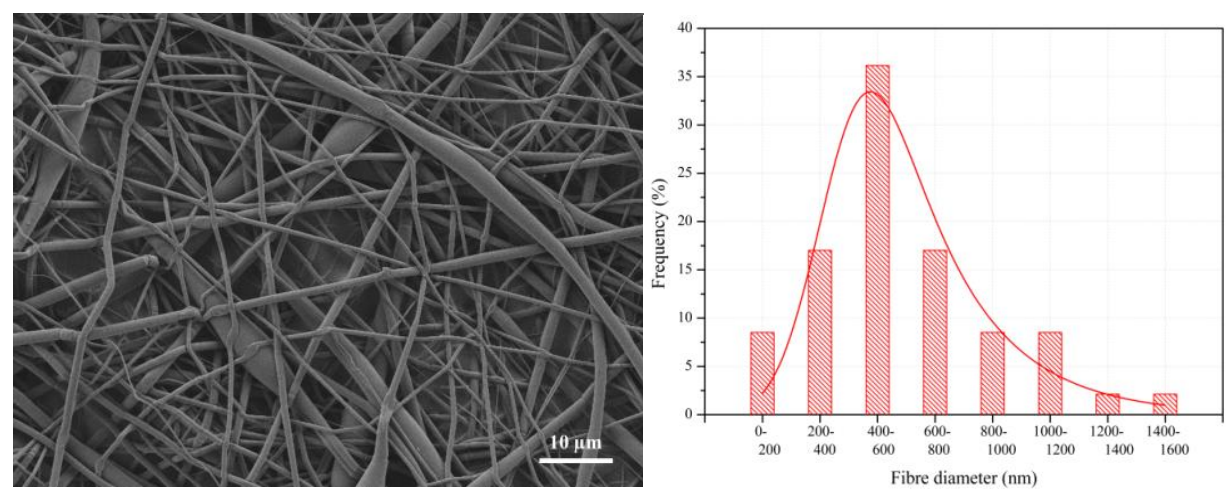

Figure 2. FE-SEM image $(3 \mathrm{kV}, 1000 \mathrm{x}, 10 \mu \mathrm{m})$ and fibre diameter histogram of PLGA nanofibrous scaffold.

The chemical composition of the scaffold was assessed by means of infrared spectroscopy (FTIR). The typical infrared spectra of a given polyester shows the characteristic bands corresponding to specific functional groups in the polymer structure. The spectra of the PLGA shows two different characteristic bands corresponding to each one of the monomers. The first band located at 1452 $\mathrm{cm}^{-1}$ corresponds to the asymmetric bending of $-\mathrm{CH}_{3}$ from the lactic units and the second one is located at $1422 \mathrm{~cm}^{-1}$ and corresponds to the bending of $-\mathrm{CH}_{2}$ - from the glycolic units of the 
O. Gil-Castell, J. D. Badia, I. Ontoria-Oviedo, D. Castellano, B. Marco, A. Rabal, J. J. Bou, A. Serra, L. Monreal, M. Blanes, P. Sepúlveda, A. Ribes-Greus. In vitro validation of biomedical polyester-based scaffolds: Poly(lactide-coglycolide) as model-case. Polymer Testing 2018;66:256-267

copolymer. Thus, the relative quantity of lactic and glycolic units could be estimated by the relative intensities of these two bands by means of Equation 5 and Equation 6, respectively [20],

$$
\begin{aligned}
& C_{L}=\frac{I_{1452}}{I_{1422}+I_{1452}} \quad(\text { Equation 5) } \\
& C_{G}=\frac{I_{1422}}{I_{1422}+I_{1452}} \quad(\text { Equation 6) }
\end{aligned}
$$

where $I_{1452}$ and $I_{1422}$ are the intensities of the bands at $1452 \mathrm{~cm}^{-1}$ and $1422 \mathrm{~cm}^{-1}$, respectively. The scaffold composition was revealed to be close to 1:1 ratio of glycolic-lactic units (56:44).

The molar mass analysis was performed by means of size exclusion chromatography (SEC) in terms of number average molar mass $\left(M_{n}\right)$ and weight average molar mass $\left(M_{w}\right)$. Result showed values around $45000 \mathrm{~g} \cdot \mathrm{mol}^{-1}$ for $M_{n}$ and $87000 \mathrm{~g} \cdot \mathrm{mol}^{-1}$ for $M_{w}$.

Table 1. Porosity, fibre diameter, composition and average molar masses of initial PLGA scaffold.

\begin{tabular}{cccccccc}
\hline & $\begin{array}{c}\boldsymbol{\rho}_{s} \\
\left(\boldsymbol{g} \cdot \mathbf{m}^{-\mathbf{2}}\right)\end{array}$ & $\begin{array}{c}\emptyset \\
(\boldsymbol{\%})\end{array}$ & $\begin{array}{c}\mathrm{d} \\
(\mathbf{n m})\end{array}$ & $\begin{array}{c}\boldsymbol{C}_{G} \\
(\boldsymbol{\%})\end{array}$ & $\begin{array}{c}\boldsymbol{C}_{\boldsymbol{L}} \\
(\boldsymbol{\%})\end{array}$ & $\begin{array}{c}\boldsymbol{M}_{\boldsymbol{n}} \\
\left(\mathbf{g} \cdot \mathbf{m o l}^{-\mathbf{1}}\right)\end{array}$ & $\begin{array}{c}\boldsymbol{M}_{w} \\
\left(\mathbf{g} \cdot \mathbf{m o l}^{-\mathbf{1}}\right)\end{array}$ \\
\hline PLGA scaffold & 2.6 & 85 & 617 & 56 & 44 & 45000 & 87000 \\
\hline
\end{tabular}

Table 1 gathers the surface density, porosity, average fibre diameter, copolymer composition and average molar mass of the initial scaffold. As a result of the preliminary characterisation, the polyester based (PLGA) scaffold was revealed to accomplish the specifications to be used as a model case.

\subsection{In vitro hydrolytic degradation}

The hydrolytic degradation of polyester-based scaffolds under abiotic aqueous environments is known to take place through breakage of the ester bonds, exponentially auto-catalysed by the presence of carboxylic groups [17]. The microstructural changes occurred in the scaffold induce the formation of macroscopic pores or cracks and the loss of monomeric and oligomeric species, thus reducing the mass of the polymers and finally decomposing their architecture until bioassimilation or excretion [18].

The results of the monitoring of the scaffold along the in vitro hydrolytic degradation in ultrapure water and PBS are plotted in Figure 3, under the same temporal X-axis in order to compare the response given by different techniques. Parameters such as (a) mass, (b) average molar mass in number $\left(M_{n}\right)$, (c) temperature of the peak of the endotherm superimposed to the glass transition $\left(T_{g t-P}\right),(\mathrm{d}) \mathrm{pH},(\mathrm{e})$ conductivity and (f) amount of acid released were chosen for the degradation characterisation. A deep explanation is hereinafter given in each subsection in order to get a glance of the performance of each key indicator chosen for the analysis.

\subsubsection{Mass-loss}

Mass-loss evolution was measured on the sample-vial assembly by gravimetric analysis, which is the most commonly used parameter as indicator of degradation. For the case of PLGA scaffolds, the mass-loss profile was similar under both water and PBS media during the first 30 days, as shown in Fig. 3a. However, after 30 days, the remaining mass of degraded PLGA scaffolds followed different patterns depending on the medium of degradation. Under water, PLGA started to disintegrate until completion after $\sim 60$ days, with an important slope at its degradation profile. In contrast, under PBS, the mass of the scaffold remained almost constant until $\sim 90$ days. After 
O. Gil-Castell, J. D. Badia, I. Ontoria-Oviedo, D. Castellano, B. Marco, A. Rabal, J. J. Bou, A. Serra, L. Monreal, M. Blanes, P. Sepúlveda, A. Ribes-Greus. In vitro validation of biomedical polyester-based scaffolds: Poly(lactide-coglycolide) as model-case. Polymer Testing 2018;66:256-267

that, a drop of mass took place after $\sim 125$ days with a similar slope than that shown under water. The samples were then completely disintegrated after $\sim 150$ days. These results were in accordance with those reported for other scaffolds of PLGA where similar degradation extents were found [27], [28]. 
O. Gil-Castell, J. D. Badia, I. Ontoria-Oviedo, D. Castellano, B. Marco, A. Rabal, J. J. Bou, A. Serra, L. Monreal, M. Blanes, P. Sepúlveda, A. Ribes-Greus. In vitro validation of biomedical polyester-based scaffolds: Poly(lactide-coglycolide) as model-case. Polymer Testing 2018;66:256-267
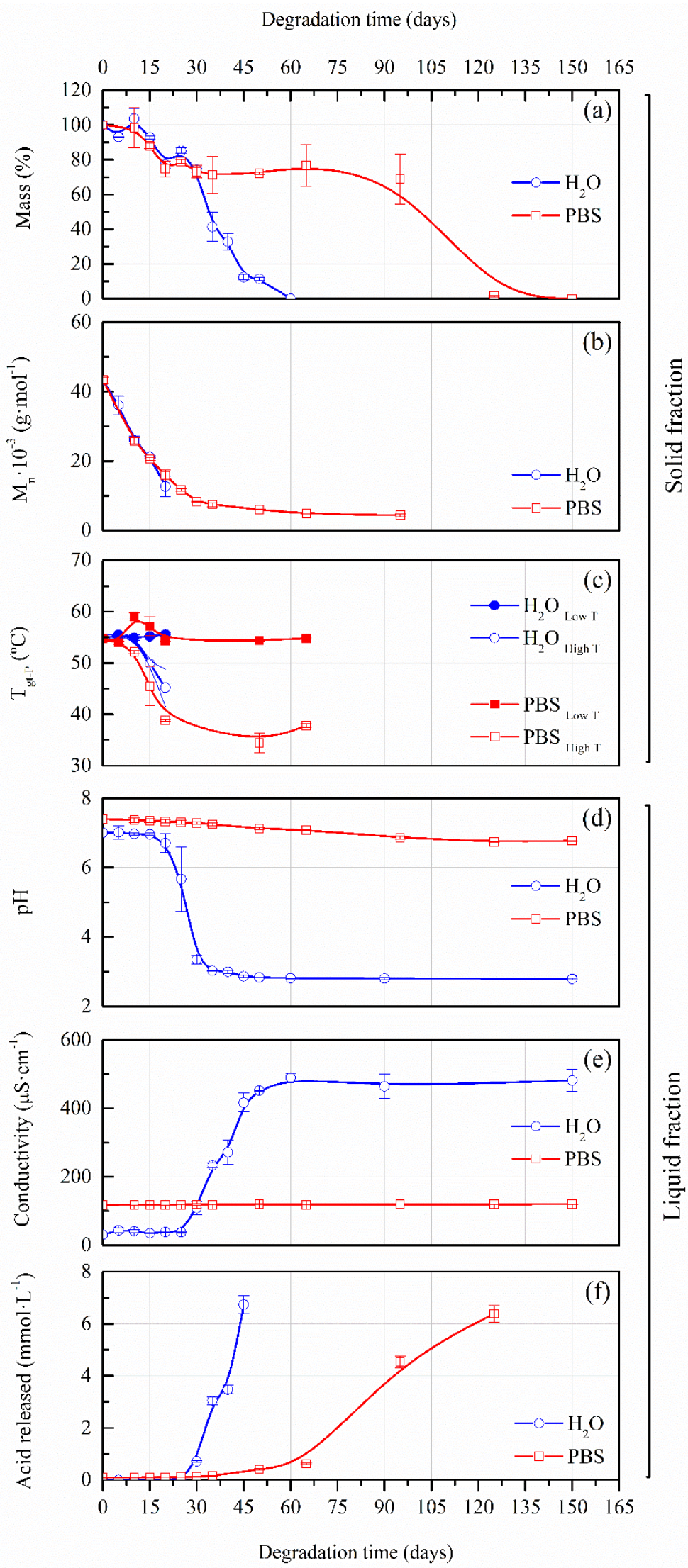

Figure 3. Evolution of hydrolytic degradation indicators for PLGA scaffolds in ultra-pure water and phosphate buffer solution (PBS): (a) mass, (b) average molar mass in number $\left(M_{n}\right)$, (c) temperature of the peak of the endotherm superimposed to the glass transition $\left(T_{g t-P}\right)$, (d) $\mathrm{pH}$, (e) conductivity and (f) amount of acid released. 
O. Gil-Castell, J. D. Badia, I. Ontoria-Oviedo, D. Castellano, B. Marco, A. Rabal, J. J. Bou, A. Serra, L. Monreal, M. Blanes, P. Sepúlveda, A. Ribes-Greus. In vitro validation of biomedical polyester-based scaffolds: Poly(lactide-coglycolide) as model-case. Polymer Testing 2018;66:256-267

\subsubsection{Molar mass}

The in vitro hydrolytic degradation was monitored in terms of molar mass by means of size exclusion chromatography (SEC). The average molar mass in number $\left(M_{n}\right)$ was considered as the most representative parameter of this analysis, which results are plotted in Fig. $\mathbf{3 b}$.

As a result of the hydrolytic degradation of the ester bond and the subsequent chain scission, a shift of the molar mass towards lower values was expected. Actually, when the PLGA scaffolds were submerged into water, a continuous linear fall from initial $M_{n}$ values $\sim 45 \cdot 10^{3} \mathrm{~g} \cdot \mathrm{mol}^{-1}$ to values $\sim 15 \cdot 10^{3} \mathrm{~g} \cdot \mathrm{mol}^{-1}$ up to $\sim 20$ days was found. Afterwards, the samples were impossible to handle. Under PBS, the decay was monitored up to $\sim 95$ days, adapting the profile to an apparent exponential decrease function, until $M_{n}$ values $\sim 5 \cdot 10^{3} \mathrm{~g} \cdot \mathrm{mol}^{-1}$. After that, the specimens were entirely collapsed and no more analyses could be carried out. These results were in agreement with literature [20], [21], [28].
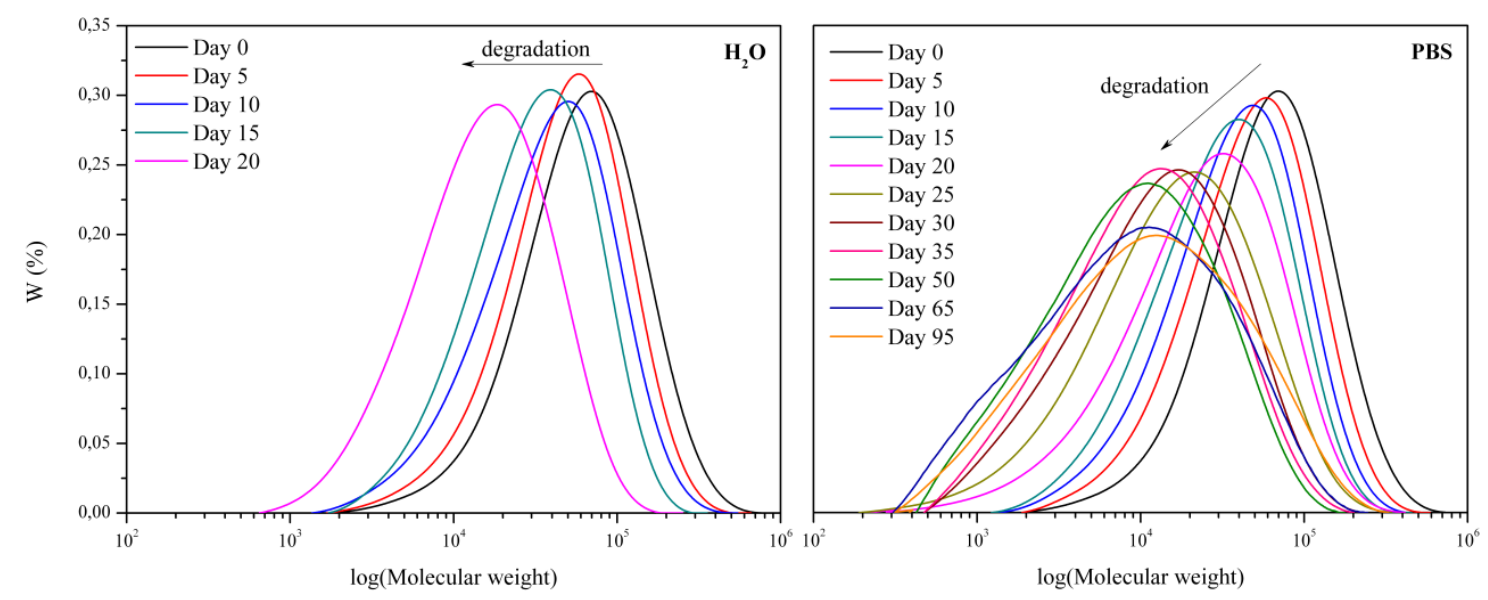

Figure 4. Molar mass distributions of PLGA scaffolds exposed to hydrolytic degradation in ultra-pure water (left) and PBS (right).

Deeper insight could be obtained from SEC analyses. Figure 4 shows the molar mass distributions of the PLGA scaffolds subjected to ultra-pure water and PBS media. A unimodal distribution was observed for non-exposed PLGA, which exhibited a sharp peak at $100 \mathrm{kDa}$. When exposed to ultra-pure water, the molar mass distribution were displaced to lower molar masses, slightly increasing their width. A breakage of the ester bonds seemed to take place for long polymer chains, producing a broader distribution of chain sizes. After $\sim 20$ days of degradation, the peak was located around $10 \mathrm{kDa}$. In contrast, scaffolds immersed in PBS showed a different degradation pattern. Until $\sim 30$ days, a diminution of the height and a broadening of the peaks were observed. The height and shape of the peak was practically maintained from day 30 to day 50 but displaced towards lower molar masses, suggesting that all polymeric chains were equally degraded. The lowest values of molar mass were reached after $\sim 20$ and $\sim 95$ days in water and PBS, respectively. The formation of different segmental-size populations was suggested, due to the appearance of multi-modal curves caused by the particular hydrolysis mechanism [18]. 
O. Gil-Castell, J. D. Badia, I. Ontoria-Oviedo, D. Castellano, B. Marco, A. Rabal, J. J. Bou, A. Serra, L. Monreal, M. Blanes, P. Sepúlveda, A. Ribes-Greus. In vitro validation of biomedical polyester-based scaffolds: Poly(lactide-coglycolide) as model-case. Polymer Testing 2018;66:256-267

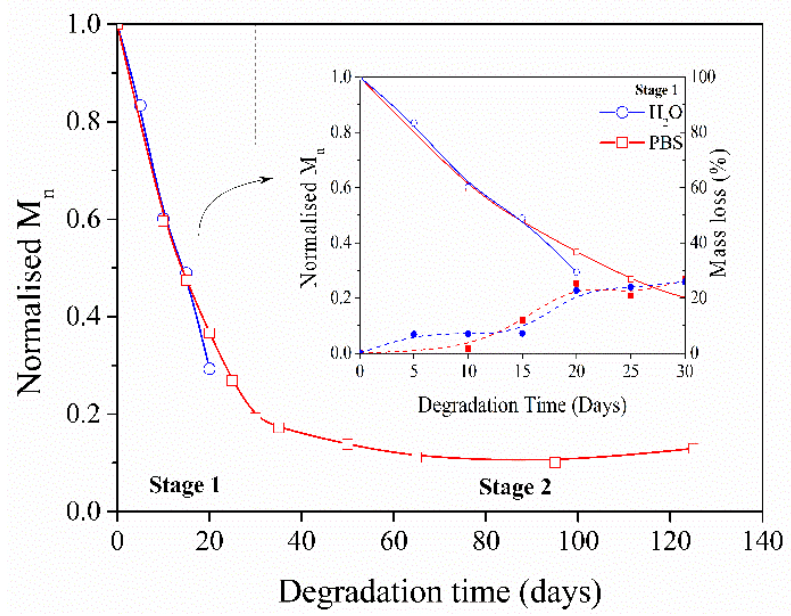

Figure 5. Normalised average molar mass in number $\left(M_{n}\right)$ as a function of the exposure time of PLGA scaffolds to ultra-pure water and PBS. Inset: Detail of the stage 1 from immersion to day $30^{\text {th }}$. Mass loss is included as dotted lines.

The degradation kinetics were studied in Figure 5, where the normalized value of $M_{n}$ is plotted as a function of the degradation time. As commented above, samples subjected to degradation in ultra-pure water after 20 days were impossible to handle so that the degradation mechanism was mainly studied for the PBS medium. According to the mass-loss evolution (Fig. 3a), two well differentiated stages could be observed. In the inset of Fig. 5 the normalized number-average molar mass and the mass-loss are plotted as a function of time. A stage 1 was defined between day 0 and day 30. The non-linear behaviour of the mass loss perceived in this stage in both media suggested an autocatalytic predominant random scission [40]. However, the presumable acidification of the medium when immersed in water, may had promoted more autocatalytic hydrolysis reactions [17], [18]. Several studies found that a combination of random and end scission is the most common mechanism as well as that an autocatalytic process is more often expected than non-catalytic hydrolysis [41], [42]. From day 30 onwards, the stage 2 was observed. While the samples in water were completely disintegrated, a deceleration of the $M_{n}$ variation could be perceived in the PBS medium, which was indicative of a non-catalytic hydrolysis contribution. This lower catalytic behaviour in PBS was due to the capability of PBS to buffer the acidification of the media which would be supposed to have occurred due to the released low molecular weight acidic species.

\subsubsection{Thermal properties}

The use of differential scanning calorimetry is essential to understand the thermal properties of polymers subjected to different degrading conditions [43]-[50]. Indicators of degradation such as the cold-crystallization temperature [44], the partial melting areas [45], the crystallinity degree [51], the relative partial crystallinity or the balance among amorphous and rigid amorphous fractions [52] have been previously proposed for monitoring degradation.

For PLGA scaffolds, no relevant cold-crystallisation and melting behaviours were observed, which ensured that no formation of significant crystalline fractions that could difficult the bioassimilation of scaffolds by macrophagues was produced. Figure 6 shows the DSC traces of the first heating scan of non-exposed PLGA and those subjected to in vitro hydrothermal degradation in both media. The analysis was thus focused on the temperature region from 0 to $100^{\circ} \mathrm{C}$, where the glass transition and the endothermic enthalpy associated to the release of energy accumulated during physical annealing at temperatures below the glass transition are shown. This 
O. Gil-Castell, J. D. Badia, I. Ontoria-Oviedo, D. Castellano, B. Marco, A. Rabal, J. J. Bou, A. Serra, L. Monreal, M. Blanes, P. Sepúlveda, A. Ribes-Greus. In vitro validation of biomedical polyester-based scaffolds: Poly(lactide-coglycolide) as model-case. Polymer Testing 2018;66:256-267

sharp endotherm was revealed at short degradation times, and became broader the longer the hydrolytic exposure was. This phenomenon variated from unimodal to bimodal after 15-20 days, which was ascribed to the different glass transitions of the components of the copolymer, i.e. poly(glycolide) (PGA), between 35 and $40{ }^{\circ} \mathrm{C}$, and poly(lactide) (PLA), between 55 and $60{ }^{\circ} \mathrm{C}$ [53].

The temperatures of the peaks of the endotherm superimposed to the glass-transition $\left(T_{g t-P}\right)$ were chosen as indicators of degradation, as plotted in Fig. 3c. The initial $T_{g t-P}$ values were located around $54.5^{\circ} \mathrm{C}$, which decoupled towards high temperature (high- $\mathrm{T}$ ) and low temperature peaks (low-T). The low-T peak, decreased to $\sim 45{ }^{\circ} \mathrm{C}$ under water and to $\sim 35{ }^{\circ} \mathrm{C}$ under PBS, corresponding to a $17 \%$ and a $35 \%$ of reduction, respectively, with similar fashion as that shown by mass-loss. These results are in concordance with other reports that suggested a more preferential hydrolytic degradation of the glycolic-glycolic and glycolic-lactic ester linkages, in contrast to that of the lactic-lactic bond in random poly(lactide-co-glycolide) polymer chains [54]. Thus, the generation of the independent homopolymeric new segments of poly(lactic acid) and poly(glycolic acid) would contribute to the appearance of separated glass transition events.
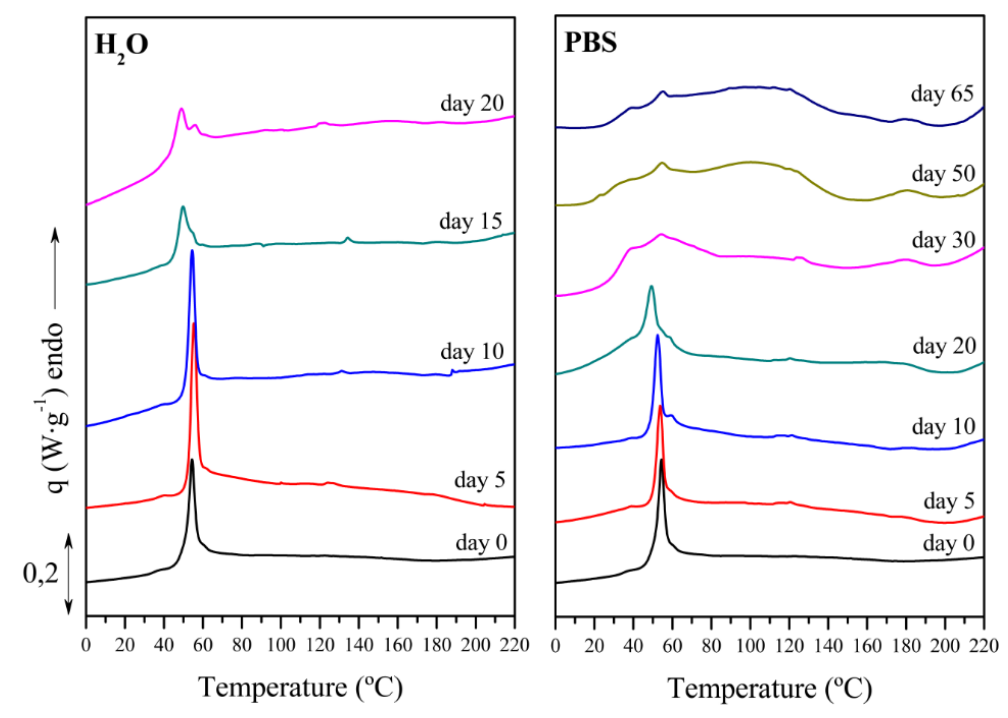

Figure 6. First heating DSC traces for PLGA scaffold after immersion in ultra-pure water and PBS as a function of the exposure time.

\subsubsection{Surface morphology}

The surface morphology of the scaffolds subjected to the in vitro hydrolytic degradation procedure was assessed by means of field-emission scanning electron microscopy (FE-SEM) as a function of the exposure time. Figure 7 shows the surface micrographs of PLGA scaffolds submitted to both media after 5, 10 and 15 days of immersion. Afterwards, handling samples was not possible.

In particular, for PLGA scaffolds immersed in water, a general coalescence, and loss of the initial nanofibrous arrangement as well as growth of pores was perceived. Fibres swelled and seemed to coalesce after 5 days of exposition. After 10 days of immersion, coalescence increased and pores seemed to appear in the surface of scaffolds. Finally, after 15 days, the structure completely coalesced and the pores continuously grew. This behaviour can be ascribed to the hydrolytic degradation behaviour of PLGA, in which water penetrated and diffused into fibres which substantially swelled until coalescence. Afterwards, hydrolytic degradation in bulk occurred and 
O. Gil-Castell, J. D. Badia, I. Ontoria-Oviedo, D. Castellano, B. Marco, A. Rabal, J. J. Bou, A. Serra, L. Monreal, M. Blanes, P. Sepúlveda, A. Ribes-Greus. In vitro validation of biomedical polyester-based scaffolds: Poly(lactide-coglycolide) as model-case. Polymer Testing 2018;66:256-267

pores appeared due to the release of low molar mass compounds to the hydrolytic media [18], [55]. These observations were in agreement with the results drawn from experiments of mass-loss and DSC shown in Fig. 3, in which the main degradation stage seemed to be triggered around 15 days. Indeed, the molar mass of PLGA at this stage decreased by $50 \%$, thus supporting the statement of threshold of performance in this medium.

However, when subjected to PBS, the degradation process appeared to be considerably different and slower than that observed in water. Although a swelling effect seemed to take place after 5 days of immersion, conglutination was not reached. After 10 days, swelling hardly occurred and some fibres looked to be broken or separated, showing more terminal ends. In addition, tiny holes appeared in fibres, indicating individual fibre degradation. After 15 days, similar morphology was observed but small pores became higher and deeper, due to the advance of degradation. In contrast with the experiments in water, although PLGA also showed a 50\% reduction of molar mass at this stage and the trigger of degradation was pointed out by DSC, the mass-loss profile followed a plateau stage during longer times, due to the inhibition of acidic species by PBS, thus decelerating the chain scission of the scaffolds and consequently maintaining the structure.
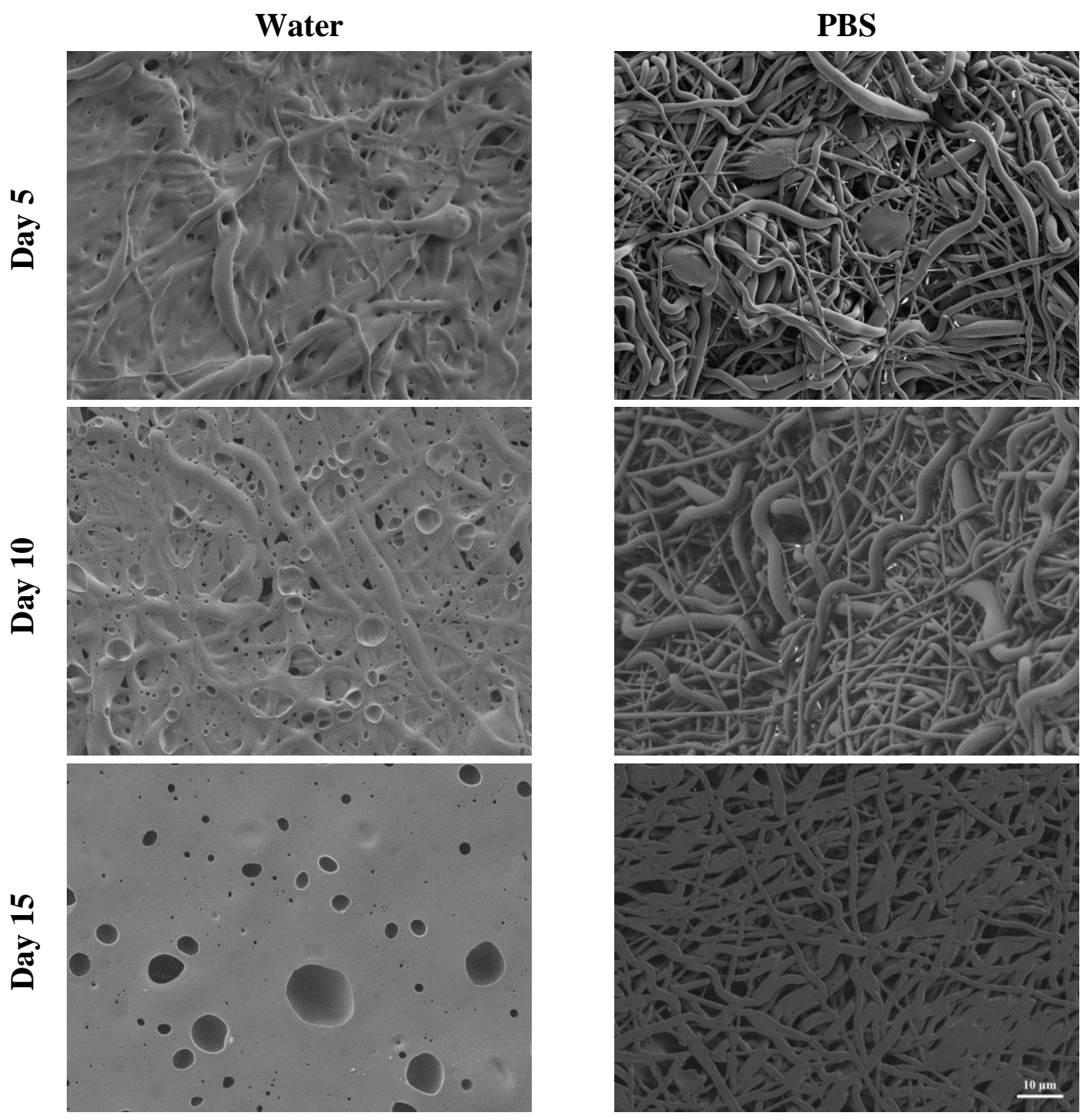

Figure 7. FE-SEM images $(3 \mathrm{kV}, 1000 \times, 10 \mu \mathrm{m})$ of the scaffold surface subjected to degradation in water (left) and PBS (right). 
O. Gil-Castell, J. D. Badia, I. Ontoria-Oviedo, D. Castellano, B. Marco, A. Rabal, J. J. Bou, A. Serra, L. Monreal, M. Blanes, P. Sepúlveda, A. Ribes-Greus. In vitro validation of biomedical polyester-based scaffolds: Poly(lactide-coglycolide) as model-case. Polymer Testing 2018;66:256-267

\subsubsection{Analysis of the hydrolytic degradation media}

Though the significance of the characterisation of the scaffolds is essential to understand the effects of the degradation on their molecular architecture and thus on their physico-chemical properties and performance, the parallel observation of the hydrolytic degrading media can offer quick information of the state of degradation and even more, fast data to infer the impact of the degradation of biopolymer polyester-based scaffolds. The evolution of the $\mathrm{pH}$, conductivity and acid released are shown in Figs. 3d, e and $\mathbf{f}$, respectively.

When immersed in water, the $\mathrm{pH}$ remained constant until day 15 , when it dramatically decreased from neutral $\mathrm{pH} \sim 7$ to acidic $\mathrm{pH} \sim 3$ around day 30, as displayed in Fig. 3d. This drop was assigned to a large release of acidic species, not only glycolic and lactic acid units but also acidic oligomers that may cause acidification of the media, according to other studies [18], [21]. In contrast, when samples were exposed to PBS, the general tendency of the $\mathrm{pH}$ was to remain almost constant along the degradation process, due to the ability of this solution to neutralise acidic species released during degradation, as previously suggested. Nonetheless a slight diminution can be considered from $\mathrm{pH} 7.4$ to $\mathrm{pH} 6.6$ in concordance with results found by other authors [56]-[60], coinciding with the main mass-loss stage in Fig. 3a.

Concerning conductivity, it showed an inversed pattern than that exhibited by $\mathrm{pH}$ at similar stages (see Fig. 3e). When measured in ultra-pure water, the conductivity remained constant showing values around $35 \mu \mathrm{S} \cdot \mathrm{cm}^{-1}$ up to $\sim 20$ days. After that, an abrupt growth was observed, reaching conductivities near to $500 \mu \mathrm{S} \cdot \mathrm{cm}^{-1}$ almost symmetrically to the $\mathrm{pH}$ evolution. However, the intrinsic conductivity of the PBS media showed such a high value that the effect of acidic species released to the media was overlapped. Conductivity remained constant around $110 \mathrm{mS} \cdot \mathrm{cm}^{-1}$, characteristic of the phosphate buffer solution.

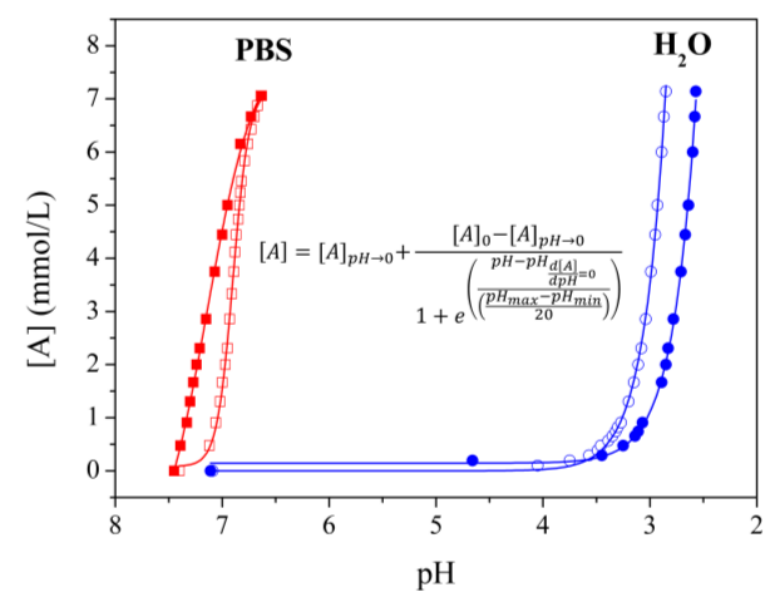

Figure 8. Titration pattern curves for water (circles) and PBS (squares) with lactic (solid) and glycolic (open) acids.

The $\mathrm{pH}$ and the release of acid species could be correlated by means of titration patterns, which were prepared for lactic and glycolic acids, as shown in Figure 8. Similar titration profiles were obtained for both species. A Boltzmann-like trend was observed in water and PBS. By measuring the $\mathrm{pH}$ of the degradation media and the aid of these curves, the amount of acid released in the degradation media as a function of time could be estimated. Thus, in Fig. 3f, a similar but delayed acid releasing profile was shown for ultra-pure water and PBS. First, a slow release period was 
O. Gil-Castell, J. D. Badia, I. Ontoria-Oviedo, D. Castellano, B. Marco, A. Rabal, J. J. Bou, A. Serra, L. Monreal, M. Blanes, P. Sepúlveda, A. Ribes-Greus. In vitro validation of biomedical polyester-based scaffolds: Poly(lactide-coglycolide) as model-case. Polymer Testing 2018;66:256-267

found, followed by a fast release stage. In ultra-pure water, the inflection point was located after $\sim 30$ days. However, in PBS, the slow release period was prolonged until $\sim 70$ days, when a fast release was found. Still, when the release was faster, it was quicker in water than in PBS, due to the autocatalytic hydrolytic reaction taking place in water, as proposed by the degradation kinetics studied by SEC.

\subsection{In vitro biocompatibility}

\subsubsection{Cell attachment and viability}

The evaluation of the cell capacity to be attached and proliferate onto the scaffolds over time is one of the fundamental approaches to take into account when assessing biocompatibility. It is known that cells attachment decrease when the scaffolds pore size is increased [61] and similar effect could be observed depending on the nanofibrous arrangement. For this purpose, fibroblasts were seeded onto the PLGA scaffold and cultured along 48 and $96 \mathrm{~h}$. Then, the cells were nuclear stained with DAPI. A great number of cell was observed in both conditions, as shown in Figure 9a, indicating that PLGA supported cell adhesion. Indeed, scanning electron microscope images from scaffolds cultured during $48 \mathrm{~h}$ revealed that the cells were completely attached to the scaffold and formed a continuous layer, covering the whole surface (Figure 9b). The cell proliferation was also measured by MTT assay. As expected, cells were able to grown on the scaffold after 48 and $96 \mathrm{~h}$. It was observed a slight increase of proliferation over the time, which results are plotted in Figure 9c.

\subsubsection{Inflammatory response of cells}

When assessing biocompatibility, the study of whether the scaffold induces an inflammatory response on the cells is crucial [33], [62]. Among other methods to evaluate the inflammatory response, pyrogenic test is one of the fastest methods, giving as a result quite relevant information. In vitro pyrogen test method recommended by the FDA requires the measurement of IL- 6 and IL1 beta as pro-inflammatory cytokines. In this particular case, we decided to include TNF-a as well to make the assay more robust and IL-10 as an indicator of a potential anti-inflammatory effect. Peripheral blood mononuclear cells (PBMCs) were cultured onto PLGA scaffolds during $5 \mathrm{~h}$ and subsequently RNA was extracted for gene expression analysis. Cells were also incubated with PHB as positive control, as it is a widely used polymer in regenerative medicine [38], [63]. Cells cultured without any scaffold were considered as negative control. IL-1 $\beta$ (interleukin $1 \beta$ ) expression was induced after culture with PLGA scaffolds but values were lower than those observed with PHB scaffolds. Same results were observed with IL-6 (interleukin 6), IL-10 (interleukin 10) and TNF (tumor necrosis factor), as observed in Figure 9d. 
O. Gil-Castell, J. D. Badia, I. Ontoria-Oviedo, D. Castellano, B. Marco, A. Rabal, J. J. Bou, A. Serra, L. Monreal, M. Blanes, P. Sepúlveda, A. Ribes-Greus. In vitro validation of biomedical polyester-based scaffolds: Poly(lactide-coglycolide) as model-case. Polymer Testing 2018;66:256-267

a)
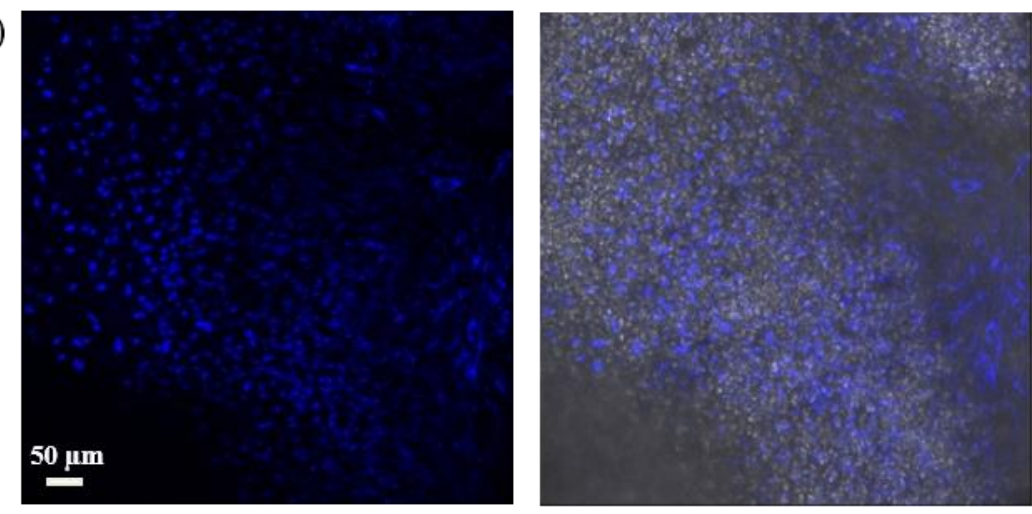

b)
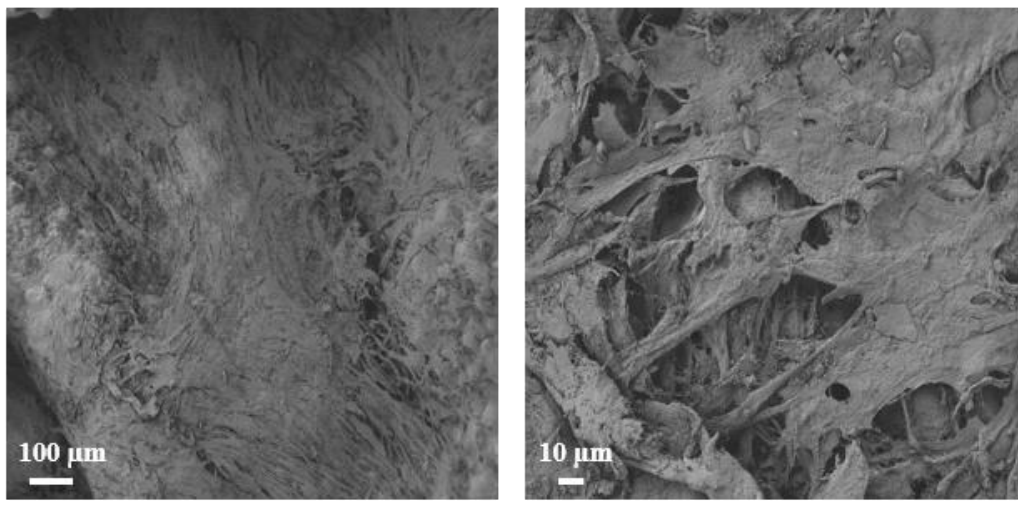

c)

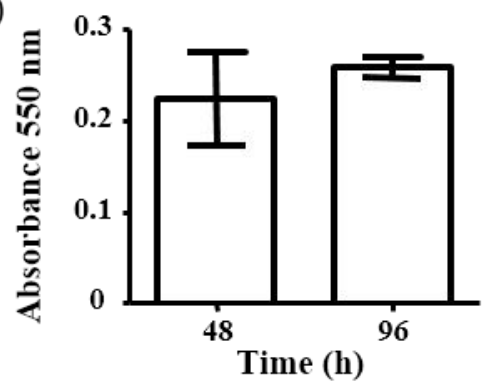

d)

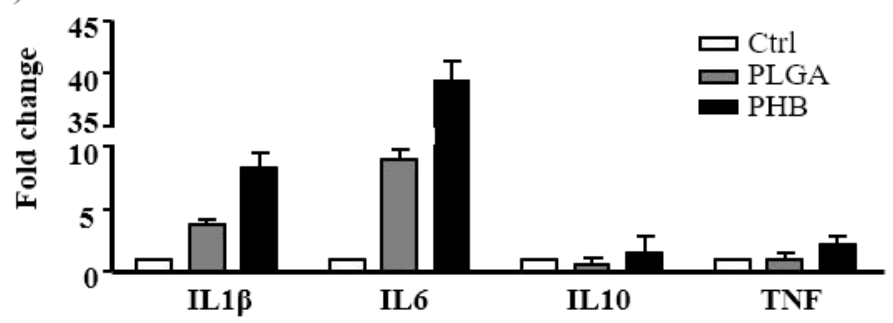

Figure 9. (a) Nuclear staining with DAPI of human fibroblasts cultured on PLGA scaffolds for $48 \mathrm{~h}$ (left) and overlapping images of DAPI and transmitted light (right). Scale bar $50 \mu \mathrm{m}$; (b) Scanning electron microscope images of fibroblasts cultured during $48 \mathrm{~h}$ in PLGA scaffolds. Scale bars $100 \mu \mathrm{m}$ (left) and 10 $\mu \mathrm{m}$ (right); and (c) Fibroblasts viability on PLGA scaffolds measured at $48 \mathrm{~h}$ and $96 \mathrm{~h}$ by MTT assay. Absorbance was measured at $550 \mathrm{~nm}$, data are expressed as arbitrary units; (d) IL-1 $\beta$, IL-6, IL-10 and TNF gene expression of PBMCs incubated with PLGA scaffold, PHB scaffold and without any scaffold

(control).

\subsubsection{Toxicity of the monomeric constituents of the scaffold}

The hydrolytic degradation of the polyester based scaffolds generates the release of low molar mass compounds to the surrounding media of the implant. These compounds, ultimately comprise the monomeric constituents of the polymer material [18], [55]. The chemical composition of the scaffolds focused on this study is based on the copolymer poly(lactide-co-glycolide) composed of lactic and glycolic acid units. Accordingly, the study of the effect of these monomeric compounds on the cell viability in terms of the toxic concentration is substantially relevant. The MTT results are shown in Figure 10a and 10b. Human fibroblasts and Keratinocytes were incubated on different concentrations of lactic and glycolic acids. In both acids, toxicity was found at concentrations above $30 \mathrm{mM}$ which was correlated with a decrease of the absorbance measured 
O. Gil-Castell, J. D. Badia, I. Ontoria-Oviedo, D. Castellano, B. Marco, A. Rabal, J. J. Bou, A. Serra, L. Monreal, M. Blanes, P. Sepúlveda, A. Ribes-Greus. In vitro validation of biomedical polyester-based scaffolds: Poly(lactide-coglycolide) as model-case. Polymer Testing 2018;66:256-267

at $550 \mathrm{~nm}$. Conversely, no toxicity was found at lower concentrations and no differences were observed in comparison to the control sample $(0 \mathrm{mM})$.
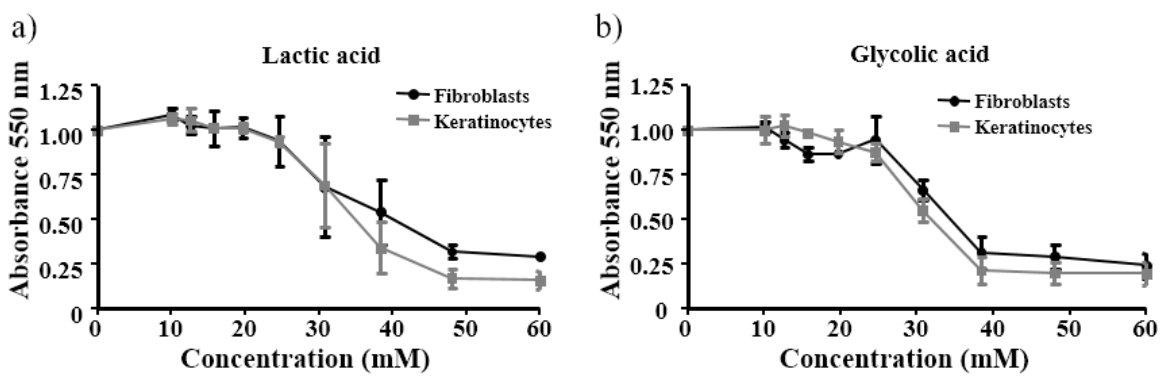

Figure 10. Toxicity evaluation for different concentrations of lactic (a) and glycolic (b) acids by MTT assay.

\subsection{Semi-quantitative comparison of monitoring techniques in terms of promptness of identification, simplicity, knowledge and cost}

Two radar-like charts, plotted in Figures 11a and 11b were considered in this study to compare the several techniques used for the in vitro validation (hydrolytic degradation and biocompatibility, respectively) for a polyester based scaffold. Aspects such as the promptness of identification, the simplicity of obtaining results, the depth of offered knowledge, and the cost of the techniques need to be taken into account in order to offer a general overview of techniques. Accordingly, techniques were inter-compared in terms of the cited aspects and rated based on a Likert-scale with a range of 1 to 5, where 1 denoted the lowest desired value and 5 the highest desired value for the appropriate evaluation of the technique for every factor of comparison. For the sake of clearness, it is important to remark that the square bound by corners represent the most convenient value for each variable. Thus, the highest frame square should represent the cheapest, simplest and promptest technique, which also provides more knowledge about what is happening during the degradation.

All the techniques and results shown above offer a particular and specific vision of the in vitro validation of polyester based scaffolds for biomedical applications, since each method possesses some characteristics that differentiate it from others. The appropriate analysis of these characteristics would result in a useful picture to set up a suitable plan of analysis for the in vitro validation of polyester-based scaffolds depending on the balance between the interest in ascertaining the trigger of the process or going deeper into the knowledge of the causes and effects along validation. 

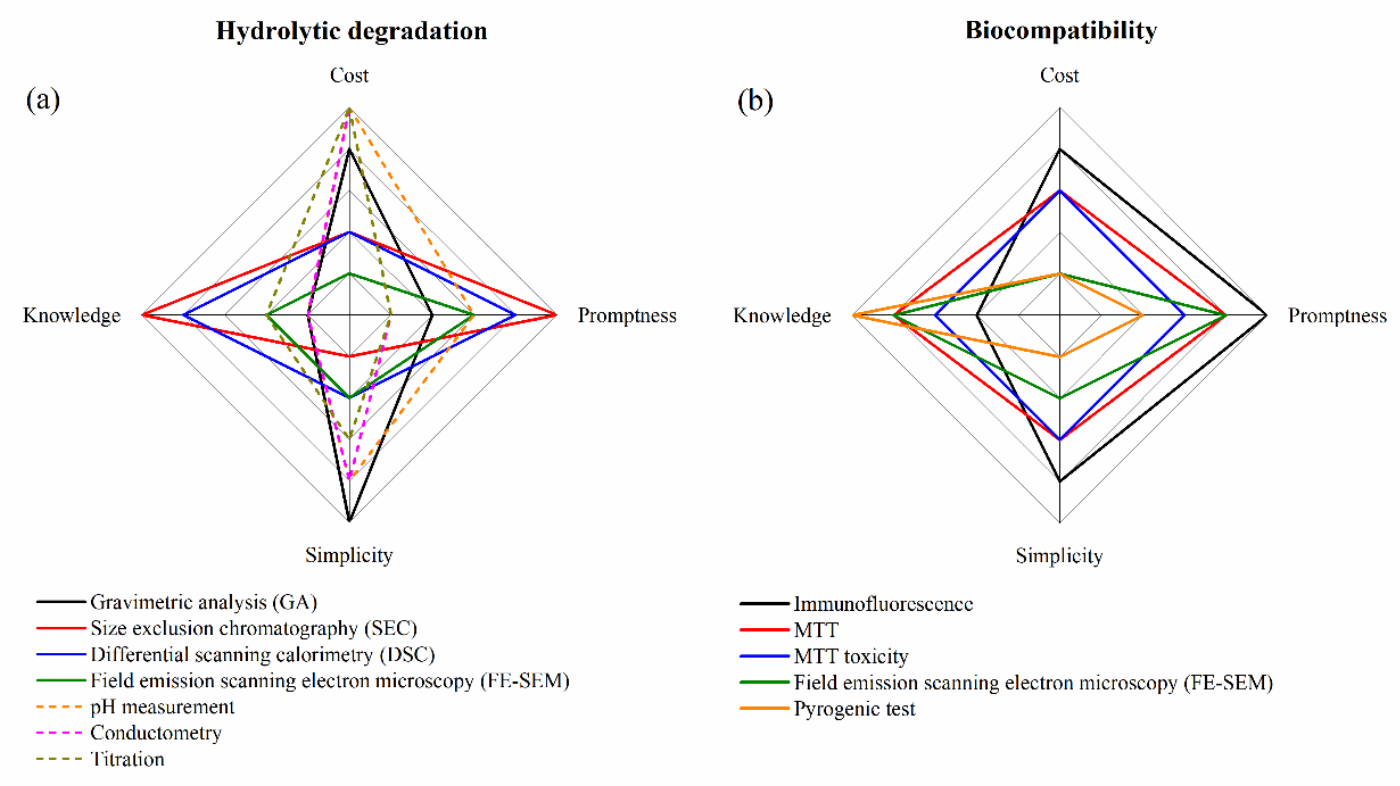

Figure 11. Radar-like chart comparing techniques for the in vitro validation of a polyester based scaffold in terms of (a) hydrolytic degradation and (b) biocompatibility according to promptness of identification, simplicity, depth of knowledge and favourable cost of the technique.

A comparison of the response of a set of different materials and/or formulations to an in vitro validation procedure can be expensive and highly time-consuming if all the techniques are applied. However, a fast trial to choose the right material according to the performance needs may be practical considering promptness of identification. The rapidness of identification of degradation is essential in preliminary tests. Hydrolytic degradation can be identified after a month of exposure for the majority of techniques. However, techniques such as SEC and DSC can offer information at shorter times, being the former extremely accurate in measuring degradation from the very beginning. Biocompatibility assays give, in general, a fast response in comparison to the study of the hydrolytic degradation. The immunofluorescence, MTT, FE-SEM, pyrogenic test and MTT toxicity assays bring results in a relative short time-span.

The estimation of the simplicity of the techniques is relevant when aspects such as the proficiency needed to become expert in the technique to prepare samples and experiments, run tests and postoperate the results appropriately are considered. There are some techniques which are easy and simple to use, as the $\mathrm{pH}$ or conductivity measurements, the gravimetric analysis and the titration for ascertaining the hydrolytic degradation and immunofluorescence to assess biocompatibility, where one almost immediately gets the results without exhaustive preparation and post-data treatment. However, some other techniques such as FE-SEM, SEC, DSC or MTT assays require accurate sample preparation and a thorough procedure to perform the experiment and analyse the results. Pyrogenic test is also a highly complex technique in terms of preparation and performance of the experiments as well as during the interpretation of results.

The cost and maintenance of the techniques also plays an important role that needs to be taken into account. Some expensive and specific measurements were carried out by FE-SEM, DSC and SEC to understand degradation mechanisms. In contrast, ready available techniques used to identify and monitor the degradation profile were gravimetric analysis, $\mathrm{pH}$ measurement, conductometry and titration, which are considered as cheap, simple and easy-to-access techniques. In terms of cost, biocompatibility assays showed high variation. The pyrogenic test 
O. Gil-Castell, J. D. Badia, I. Ontoria-Oviedo, D. Castellano, B. Marco, A. Rabal, J. J. Bou, A. Serra, L. Monreal, M. Blanes, P. Sepúlveda, A. Ribes-Greus. In vitro validation of biomedical polyester-based scaffolds: Poly(lactide-coglycolide) as model-case. Polymer Testing 2018;66:256-267

was the most expensive validation technique for the biocompatibility assessment, followed by the FE-SEM analysis, if compared to MTT and immunofluorescence assays. Actually, immunofluorescence is an economic technique that should be complemented with other assays. MTT and toxicity assays are techniques that offer interesting results at a reasonable cost.

The depth of knowledge permits distinguishing techniques according to the level, wideness and variety of results that can be obtained. In-depth techniques such as SEC and DSC offer results from which a great number of suggestions and explanations of the degradation mechanism can be obtained, as well as permits infer consequences on the physico-chemical properties. Conversely, there are other single-result techniques that offer a macroscopic observation of mass, $\mathrm{pH}$ or conductivity, which might render information about the occurrence of degradation, but not about its state. FE-SEM and titration would be in the middle of the proposed score, since they endow useful information suggesting some mechanism of degradation. Pyrogenic test and MTT assay give an overview on how inflammatory and toxic is a polymeric scaffold. Both techniques are required when validating the biocompatibility of a given biomedical device. The evaluation of the toxicity of the monomeric constituents of the polymer material is also essential to determine the maximum tolerable concentration of such compounds when released during the hydrolytic degradation. However, although the results obtained from immunofluorescence assay showed that cells are actually attached and spread onto the scaffold, this technique do not offer such knowledge as the pyrogenic test, the FE-SEM and the MTT assays.

\section{Conclusions}

Monitoring and understanding the in vitro behaviour of polyester-based scaffolds, both comprising the study of the hydrolytic degradation and the biocompatibility is essential to ensure the desired performance, according to a given biomedical purpose. Poly(lactide-co-glycolide) (PLGA) scaffolds were considered as a model-case for polyester-based devices to compare the performance of different analytical techniques to monitor the in vitro hydrolytic degradation and biocompatibility.

The suitability of techniques for the in vitro validation procedure was evaluated in terms of the promptness of identification, simplicity of obtaining results, depth of offered knowledge, and cost and maintenance. Results showed a useful picture to set up an appropriate plan of analysis of the degradation of polyester-based scaffolds depending on the balance between the interest in ascertaining the trigger of degradation or deep into the knowledge of the causes and effects along validation.

When assessing the hydrolytic degradation, the size exclusion chromatography and the differential scanning calorimetry were found to be the techniques that offered deeper knowledge and promptness of identification. However, these techniques are costly and complex to evaluate. Conversely, economic and simple techniques as the gravimetric analysis of the scaffold and the $\mathrm{pH}$ and conductivity measurements in the degradation media were considered, which offered little knowledge and late identification of the degradation.

Regarding the biocompatibility evaluation, the pyrogenic test is the most specific that brings more knowledge about the cell's response when seeded into the scaffold. Then, the MTT assay both for the scaffold and the monomeric constituents of the polymer was found to be an equilibrated technique in terms of the studied parameters. The immunofluorescence test was the simplest and the promptest technique at a favourable cost, that brings information about the cell viability and distribution onto the scaffold. In order to deeply evaluate the cell morphology and distribution, 
O. Gil-Castell, J. D. Badia, I. Ontoria-Oviedo, D. Castellano, B. Marco, A. Rabal, J. J. Bou, A. Serra, L. Monreal, M. Blanes, P. Sepúlveda, A. Ribes-Greus. In vitro validation of biomedical polyester-based scaffolds: Poly(lactide-coglycolide) as model-case. Polymer Testing 2018;66:256-267

costly techniques such as FE-SEM are needed. This technique gives an accurate overview of the cell morphology and appearance over the scaffold surface.

These results can be of interest to researchers, technologists and physicians who plan to study the balance between performance and degradation of polyester-based scaffolds in a cost-effective way, depending on the focus of the test, i.e. from quick discarding trials according to simple promptness of identification, to a detailed tailoring of compositions according to the in-depth knowledge of the physico-chemical reasons behind the behaviour under physiological conditions.

\section{Acknowledgements}

The authors would like to acknowledge the Spanish Ministry of Education, Culture and Sports for the predoctoral FPU grant of O. Gil-Castell (FPU13/01916). Generalitat Valenciana is thanked for the APOSTD/2014/041 for J.D. Badia. D. Castellano and I. Ontoria-Oviedo thanked RESOLTEX (Ministry of Economy, Industry and Competitiveness RETOS, RTC-2015-4185-1) and P. Sepúlveda acknowlewdges ISCIII for I3SNS Program.

\section{Bibliography}

[1] S. Shalaby, Ed., Biomedical Polymers: Designed-to-Degrade Systems. Munich: Hanser Publishers, 1994.

[2] B. D. (Buddy D. . Ratner, Biomaterials science : an introduction to materials in medicine. Academic Press, 2013.

[3] S. Stratton, N. B. Shelke, K. Hoshino, S. Rudraiah, and S. G. Kumbar, "Bioactive polymeric scaffolds for tissue engineering," Bioact. Mater., vol. 1, no. 2, pp. 93-108, Dec. 2016.

[4] F. Pati, J. Jang, D.-H. Ha, S. Won Kim, J.-W. Rhie, J.-H. Shim, D.-H. Kim, and D.-W. Cho, "Printing threedimensional tissue analogues with decellularized extracellular matrix bioink," Nat. Commun., vol. 5, p. 3935, Jun. 2014.

[5] D. Puppi, F. Chiellini, M. Dash, and E. Chiellini, "Biodegradable polymers for biomedical applications," Nova Science Publishers, Inc., 2011, pp. 545-604.

[6] P. Gunatillake, "Biodegradable synthetic polymers for tissue engineering," Eur. Cells Mater., vol. 5, pp. 116, Oct. 2003.

[7] W.-J. Li, J. A. Cooper, R. L. Mauck, and R. S. Tuan, "Fabrication and characterization of six electrospun poly( $\alpha$-hydroxy ester)-based fibrous scaffolds for tissue engineering applications," Acta Biomater., vol. 2, no. 4, pp. 377-385, Jul. 2006.

[8] S. Chung, N. P. Ingle, G. A. Montero, S. H. Kim, and M. W. King, "Bioresorbable elastomeric vascular tissue engineering scaffolds via melt spinning and electrospinning," Acta Biomater., vol. 6, no. 6, pp. 1958-1967, Jun. 2010.

[9] O. Gil-Castell, J. D. D. Badia, E. Strömberg, S. Karlsson, and A. Ribes-Greus, "Effect of the dissolution time into an acid hydrolytic solvent to tailor electrospun nanofibrous polycaprolactone scaffolds," Eur. Polym. J., vol. 87, pp. 174-187, 2017.

[10] W.-E. Teo, R. Inai, and S. Ramakrishna, "Technological advances in electrospinning of nanofibers," Sci. Technol. Adv. Mater., vol. 12, no. 1, p. 13002, 2011.

[11] D. I. Braghirolli, D. Steffens, and P. Pranke, "Electrospinning for regenerative medicine: a review of the main topics," Drug Discov. Today, vol. 19, no. 6, pp. 743-753, 2014.

[12] A. Haider, S. Haider, and I. K. Kang, "A comprehensive review summarizing the effect of electrospinning parameters and potential applications of nanofibers in biomedical and biotechnology," Arab. J. Chem., vol. In press, 2015.

[13] J. D. Badia, O. Gil-Castell, and A. Ribes-Greus, "Long-term properties and end-of-life of polymers from renewable resources,” Polym. Degrad. Stab., vol. 137, pp. 35-57, 2017.

[14] D. Liang, B. S. Hsiao, and B. Chu, "Functional electrospun nanofibrous scaffolds for biomedical applications," Adv. Drug Deliv. Rev., vol. 59, no. 14, pp. 1392-1412, Dec. 2007.

[15] S. Agarwal, A. Greiner, and J. H. Wendorff, "Functional materials by electrospinning of polymers," Prog. Polym. Sci., vol. 38, no. 6, pp. 963-991, Jun. 2013.

[16] Edith Mathiowitz, Ed., Encyclopedia of controlled drug delivery. John Wiley \& Sons, 1999.

[17] M. Hakkarainen, A.-C. Albertsson, and S. Karlsson, "Weight losses and molecular weight changes correlated with the evolution of hydroxyacids in simulated in vivo degradation of homo- and copolymers of PLA and PGA," Polym. Degrad. Stab., vol. 52, no. 3, pp. 283-291, Jun. 1996.

[18] A. Göpferich, "Mechanisms of polymer degradation and erosion," Biomaterials, vol. 17, no. 2, pp. 103-114, 
O. Gil-Castell, J. D. Badia, I. Ontoria-Oviedo, D. Castellano, B. Marco, A. Rabal, J. J. Bou, A. Serra, L. Monreal, M. Blanes, P. Sepúlveda, A. Ribes-Greus. In vitro validation of biomedical polyester-based scaffolds: Poly(lactide-coglycolide) as model-case. Polymer Testing 2018;66:256-267

Jan. 1996

[19] T. D. Farahani, A. A. Entezami, H. Mobedi, and M. Abtahi, "Degradation of Poly(D,L-lactide-co-glycolide) 50:50 Implant in Aqueous Medium," Iran. Polym. J., vol. 14, no. 8, pp. 753-763, 2005.

[20] E. Vey, C. Roger, L. Meehan, J. Booth, M. Claybourn, A. F. Miller, and A. Saiani, "Degradation mechanism of poly(lactic-co-glycolic) acid block copolymer cast films in phosphate buffer solution," Polym. Degrad. Stab., vol. 93, no. 10, pp. 1869-1876, Oct. 2008.

[21] X. S. Wu and N. Wang, "Synthesis, characterization, biodegradation, and drug delivery application of biodegradable lactic/glycolic acid polymers. Part II: biodegradation.," J. Biomater. Sci. Polym. Ed., vol. 12, no. 1, pp. 21-34, 2001.

[22] R. F. Pereira and P. J. Bártolo, "Degradation Behavior of Biopolymer-based Membranes for Skin Tissue Regeneration," Procedia Eng., vol. 59, pp. 285-291, 2013.

[23] J. Venugopal and S. Ramakrishna, "Biocompatible Nanofiber Matrices for the Engineering of a Dermal Substitute for Skin Regeneration," Tissue Eng., vol. 11, no. 5-6, pp. 847-854, May 2005.

[24] J. Yu, A.-R. Lee, W.-H. Lin, C.-W. Lin, Y.-K. Wu, and W.-B. Tsai, "Electrospun PLGA Fibers Incorporated with Functionalized Biomolecules for Cardiac Tissue Engineering," Tissue Eng. Part A, vol. 20, no. 13-14, pp. 1896-1907, Jul. 2014.

[25] H. Fouad, T. Elsarnagawy, F. N. Almajhdi, and K. A. Khalil, "Preparation and In Vitro Thermo-Mechanical Characterization of Electrospun PLGA Nanofibers for Soft and Hard Tissue Replacement," Int. J. Electrochem. Sci, vol. 8, pp. 2293-2304, 2013.

[26] M. V. Jose, V. Thomas, K. T. Johnson, D. R. Dean, and E. Nyairo, "Aligned PLGA/HA nanofibrous nanocomposite scaffolds for bone tissue engineering," Acta Biomater., vol. 5, no. 1, pp. 305-315, Jan. 2009.

[27] Y. You, B.-M. Min, S. J. Lee, T. S. Lee, and W. H. Park, "In vitro degradation behavior of electrospun polyglycolide, polylactide, and poly(lactide-co-glycolide)," J. Appl. Polym. Sci., vol. 95, no. 2, pp. 193-200, Jan. 2005.

[28] X. Zhou, Q. Cai, N. Yan, X. Deng, and X. Yang, "In vitro hydrolytic and enzymatic degradation of nestlikepatterned electrospun poly(D,L-lactide-co-glycolide) scaffolds," J. Biomed. Mater. Res. Part A, vol. 95A, no. 3, pp. 755-765, Dec. 2010.

[29] S. R. Andersson, M. Hakkarainen, S. Inkinen, A. Södergård, and A.-C. Albertsson, "Polylactide Stereocomplexation Leads to Higher Hydrolytic Stability but More Acidic Hydrolysis Product Pattern," Biomacromolecules, vol. 11, no. 4, pp. 1067-1073, Apr. 2010.

[30] A. Höglund, S. Målberg, and A.-C. Albertsson, "Assessing the Degradation Profile of Functional Aliphatic Polyesters with Precise Control of the Degradation Products," Macromol. Biosci., vol. 12, no. 2, pp. 260-268, Feb. 2012.

[31] A. Veluska, P. Olsén, K. Odelius, A. Höglund, and A.-C. Albertsson, "Selective degradation in aliphatic block copolyesters by controlling the heterogeneity of the amorphous phase," Polym. Chem., vol. 6, no. 17, pp. 3271-3282, May 2015.

[32] A. Höglund, K. Odelius, and A.-C. Albertsson, "Crucial Differences in the Hydrolytic Degradation between Industrial Polylactide and Laboratory-Scale Poly( L-lactide)," ACS Appl. Mater. Interfaces, vol. 4, no. 5, pp. 2788-2793, May 2012.

[33] D. Castellano, M. Blanes, B. Marco, I. Cerrada, A. Ruiz-Saurí, B. Pelacho, M. Araña, J. A. Montero, V. Cambra, F. Prosper, and P. Sepúlveda, "A Comparison of Electrospun Polymers Reveals Poly(3Hydroxybutyrate) Fiber as a Superior Scaffold for Cardiac Repair," Stem Cells Dev., vol. 23, no. 13, pp. 14791490, Jul. 2014.

[34] P. Sangsanoh, S. Waleetorncheepsawat, O. Suwantong, P. Wutticharoenmongkol, O. Weeranantanapan, B. Chuenjitbuntaworn, P. Cheepsunthorn, P. Pavasant, and P. Supaphol, "In Vitro Biocompatibility of Schwann Cells on Surfaces of Biocompatible Polymeric Electrospun Fibrous and Solution-Cast Film Scaffolds," Biomacromolecules, vol. 8, no. 5, pp. 1587-1594, May 2007.

[35] "ISO 3696. Water for analytical laboratory use - Specification and test methods," 1987.

[36] "ISO 10993-13. Biological evaluation of medical devices." 2010.

[37] A. K. Pathan, J. Bond, and R. E. Gaskin, "Sample preparation for SEM of plant surfaces," Mater. Today, vol. 12, no. SUPPL., pp. 32-43, 2009.

[38] R. Carrero, I. Cerrada, E. Lledó, J. Dopazo, F. García-García, M.-P. Rubio, C. Trigueros, A. Dorronsoro, A. Ruiz-Sauri, J. A. Montero, and P. Sepúlveda, "IL1 $\beta$ induces mesenchymal stem cells migration and leucocyte chemotaxis through NF-кB.," Stem Cell Rev., vol. 8, no. 3, pp. 905-16, Sep. 2012.

[39] L. A. Smith and P. X. Ma, "Nano-fibrous scaffolds for tissue engineering," Colloids Surfaces B Biointerfaces, vol. 39, no. 3, pp. 125-131, 2004.

[40] H. Tsuji, Degradation of poly (lactide)-based biodegradable materials. Nova Science Publishers, 2008.

[41] A. Gleadall, J. Pan, M.-A. Kruft, and M. Kellomäki, "Degradation mechanisms of bioresorbable polyesters. Part 1. Effects of random scission, end scission and autocatalysis," Acta Biomater., vol. 10, no. 5, pp. 22232232, May 2014.

[42] R. P. Batycky, J. Hanes, R. Langer, and D. A. Edwards, "A Theoretical Model of Erosion and Macromolecular Drug Release from Biodegrading Microspheres,” J. Pharm. Sci., vol. 86, no. 12, pp. 1464-1477, Dec. 1997. 
O. Gil-Castell, J. D. Badia, I. Ontoria-Oviedo, D. Castellano, B. Marco, A. Rabal, J. J. Bou, A. Serra, L. Monreal, M. Blanes, P. Sepúlveda, A. Ribes-Greus. In vitro validation of biomedical polyester-based scaffolds: Poly(lactide-coglycolide) as model-case. Polymer Testing 2018;66:256-267

[43] J. D. Badía, F. Vilaplana, S. Karlsson, and A. Ribes-Greus, "Thermal analysis as a quality tool for assessing the influence of thermo-mechanical degradation on recycled poly(ethylene terephthalate)," Polym. Test., vol. 28, no. 2, pp. 169-175, 2009.

[44] L. Santonja-Blasco, R. Moriana, J. D. Badía, and A. Ribes-Greus, "Thermal analysis applied to the characterization of degradation in soil of polylactide: I. Calorimetric and viscoelastic analyses," Polym. Degrad. Stab., vol. 95, no. 11, pp. 2185-2191, Nov. 2010.

[45] J. D. Badia, E. Strömberg, S. Karlsson, and A. Ribes-Greus, "Material valorisation of amorphous polylactide. Influence of thermo-mechanical degradation on the morphology, segmental dynamics, thermal and mechanical performance," Polym. Degrad. Stab., vol. 97, no. 4, pp. 670-678, Apr. 2012.

[46] O. Gil-Castell, J. D. Badia, T. Kittikorn, E. Strömberg, M. Ek, S. Karlsson, A. Ribes-Greus, E. Strömberg, M. Ek, S. Karlsson, and A. Ribes-Greus, "Impact of hydrothermal ageing on the thermal stability, morphology and viscoelastic performance of PLA/sisal biocomposites," Polym. Degrad. Stab., vol. 132, pp. 87-96, Mar. 2016.

[47] J. D. Badia, T. Kittikorn, E. Strömberg, L. Santonja-Blasco, A. Martínez-Felipe, A. Ribes-Greus, M. Ek, and S. Karlsson, "Water absorption and hydrothermal performance of PHBV/sisal biocomposites," Polym. Degrad. Stab., vol. 108, pp. 166-174, Oct. 2014.

[48] O. Gil-Castell, J. D. Badia, T. Kittikorn, E. Strömberg, A. Martínez-Felipe, M. Ek, S. Karlsson, and A. RibesGreus, "Hydrothermal ageing of polylactide/sisal biocomposites. Studies of water absorption behaviour and Physico-Chemical performance," Polym. Degrad. Stab., vol. 108, pp. 212-222, Oct. 2014.

[49] J. D. Badia and A. Ribes-Greus, "Mechanical recycling of polylactide, upgrading trends and combination of valorization techniques," Eur. Polym. J., vol. 84, pp. 22-39, 2016.

[50] O. Gil-Castell, J. D. Badia, and A. Ribes-Greus, "Suitability of blends from virgin and reprocessed polylactide: performance and energy valorisation kinetics,” Accept. Publ. J. Renew. Mater., 2017.

[51] J. D. Badia, L. Santonja-Blasco, A. Martínez-Felipe, and A. Ribes-Greus, "Hygrothermal ageing of reprocessed polylactide,” Polym. Degrad. Stab., vol. 97, no. 10, pp. 1881-1890, Oct. 2012.

[52] J. D. Badia, E. Strömberg, S. Karlsson, and A. Ribes-Greus, "The role of crystalline, mobile amorphous and rigid amorphous fractions in the performance of recycled poly (ethylene terephthalate) (PET)," Polym. Degrad. Stab., vol. 97, no. 1, pp. 98-107, Jan. 2012.

[53] I. Engelberg and J. Kohn, "Physico-mechanical properties of degradable polymers used in medical applications: a comparative study.," Biomaterials, vol. 12, no. 3, pp. 292-304, Apr. 1991.

[54] J. Li, R. M. Stayshich, and T. Y. Meyer, "Exploiting Sequence To Control the Hydrolysis Behavior of Biodegradable PLGA Copolymers,” J. Am. Chem. Soc., vol. 133, no. 18, pp. 6910-6913, May 2011.

[55] F. von Burkersroda, L. Schedl, and A. Göpferich, "Why degradable polymers undergo surface erosion or bulk erosion," Biomaterials, vol. 23, no. 21, pp. 4221-4231, Nov. 2002.

[56] C. M. Agrawal and K. A. Athanasiou, "Technique to control pH in vicinity of biodegrading PLA-PGA implants.," J. Biomed. Mater. Res., vol. 38, no. 2, pp. 105-14, 1997.

[57] J. M. Kim, K. S. Seo, Y. K. Jeong, B. L. Hai, Y. S. Kim, and G. Khang, "Co-effect of aqueous solubility of drugs and glycolide monomer on in vitro release rates from poly(D,L-lactide-co-glycolide) discs and polymer degradation.," J. Biomater. Sci. Polym. Ed., vol. 16, no. 8, pp. 991-1007, 2005.

[58] H. Li and J. Chang, "pH-compensation effect of bioactive inorganic fillers on the degradation of PLGA," Compos. Sci. Technol., vol. 65, no. 14, pp. 2226-2232, Nov. 2005.

[59] M. Ramchandani, M. Pankaskie, and D. Robinson, "The influence of manufacturing procedure on the degradation of poly(lactide-co-glycolide) 85:15 and 50:50 implants," J. Control. Release, vol. 43, no. 2-3, pp. 161-173, Jan. 1997.

[60] J. Y. Yoo, J. M. Kim, G. Khang, M. S. Kim, S. H. Cho, H. B. Lee, and Y. S. Kim, "Effect of lactide/glycolide monomers on release behaviors of gentamicin sulfate-loaded PLGA discs," Int. J. Pharm., vol. 276, no. 1-2, pp. 1-9, May 2004.

[61] C. M. Murphy, M. G. Haugh, and F. J. O’Brien, "The effect of mean pore size on cell attachment, proliferation and migration in collagen-glycosaminoglycan scaffolds for bone tissue engineering," Biomaterials, vol. 31, no. 3, pp. 461-466, Jan. 2010.

[62] B. Semete, L. I. J. Booysen, L. Kalombo, J. D. Venter, L. Katata, B. Ramalapa, J. A. Verschoor, and H. Swai, "In vivo uptake and acute immune response to orally administered chitosan and PEG coated PLGA nanoparticles," Toxicol. Appl. Pharmacol., vol. 249, no. 2, pp. 158-165, Dec. 2010.

[63] D. Castellano, A. Sanchis, M. Blanes, M. D. Pérez del Caz, A. Ruiz-Saurí, M. Piquer-Gil, B. Pelacho, B. Marco, N. Garcia, I. Ontoria-Oviedo, V. Cambra, F. Prosper, and P. Sepúlveda, "Electrospun poly(hydroxybutyrate) scaffolds promote engraftment of human skin equivalents via macrophage M2 polarization and angiogenesis," J. Tissue Eng. Regen. Med., Jan. 2017. 
O. Gil-Castell, J. D. Badia, I. Ontoria-Oviedo, D. Castellano, B. Marco, A. Rabal, J. J. Bou, A. Serra, L. Monreal, M. Blanes, P. Sepúlveda, A. Ribes-Greus. In vitro validation of biomedical polyester-based scaffolds: Poly(lactide-coglycolide) as model-case. Polymer Testing 2018;66:256-267

\section{ANNEX - OPEN ACCESS POLICIES}

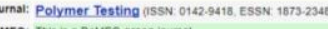

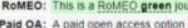

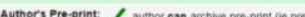

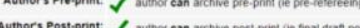

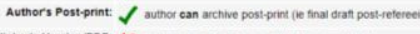

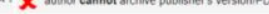

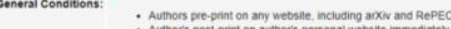

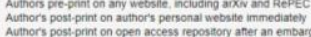

A

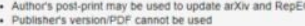
i. Aust tinx to pubither version wetn Dol Mandasted OA: (Awating intomatom) Paid Open Access: Desen Access

Now: Puobser as

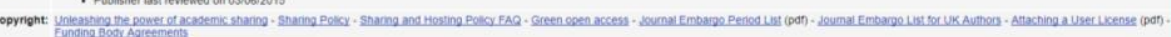

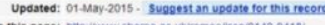

Published by: Elisevier -Geen Poices n Roured

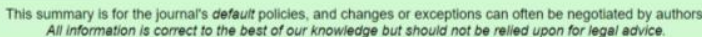

